\title{
Transient Overturning Compensation between Atlantic and Indo-Pacific Basins
}

\author{
SHANTONG SUN AND ANDREW F. THOMPSON \\ California Institute of Technology, Pasadena, California \\ IAN EISENMAN \\ Scripps Institution of Oceanography, University of California, San Diego, La Jolla, California
}

(Manuscript received 18 March 2020, in final form 2 June 2020)

\begin{abstract}
Climate models consistently project (i) a decline in the formation of North Atlantic Deep Water (NADW) and (ii) a strengthening of the Southern Hemisphere westerly winds in response to anthropogenic greenhouse gas forcing. These two processes suggest potentially conflicting tendencies of the Atlantic meridional overturning circulation (AMOC): a weakening AMOC due to changes in the North Atlantic but a strengthening AMOC due to changes in the Southern Ocean. Here we focus on the transient evolution of the global ocean overturning circulation in response to a perturbation to the NADW formation rate. We propose that the adjustment of the Indo-Pacific overturning circulation is a critical component in mediating AMOC changes. Using a hierarchy of ocean and climate models, we show that the Indo-Pacific overturning circulation provides the first response to AMOC changes through wave processes, whereas the Southern Ocean overturning circulation responds on longer (centennial to millennial) time scales that are determined by eddy diffusion processes. Changes in the Indo-Pacific overturning circulation compensate AMOC changes, which allows the Southern Ocean overturning circulation to evolve independently of the AMOC, at least over time scales up to many decades. In a warming climate, the Indo-Pacific develops an overturning circulation anomaly associated with the weakening AMOC that is characterized by a northward transport close to the surface and a southward transport in the deep ocean, which could effectively redistribute heat between the basins. Our results highlight the importance of interbasin exchange in the response of the global ocean overturning circulation to a changing climate.
\end{abstract}

\section{Introduction}

Changes in the Atlantic meridional overturning circulation (AMOC) are often linked to perturbations in surface forcing in the North Atlantic (Buckley and Marshall 2016), which constrains the formation rate of North Atlantic Deep Water (NADW). However, recent studies, which largely consider steady-state balances, have suggested that the Southern Ocean plays a leading role in setting the strength and structure of the AMOC (e.g., Marshall and Speer 2012; Ferrari et al. 2014; Cessi 2019; Johnson et al. 2019). In the adiabatic and steadystate limit, NADW returns to the sea surface through along-isopycnal upwelling in the Southern Ocean (Fig. 1) (Toggweiler and Samuels 1995; Wolfe and Cessi 2011). This relationship suggests that the AMOC should strengthen in response to intensified Southern Hemisphere westerly

Corresponding author: Shantong Sun, shantong@caltech.edu winds and Southern Ocean upwelling in a warming climate. Yet, this behavior is not realized in most state-ofthe-art climate models, which instead consistently project the AMOC strength to decline in the twenty-first century (Cheng et al. 2013).

The goal of this study is to reconcile predictions of how the AMOC responds to changes in the NADW formation rate across a range of time scales. We find that accounting for changes in the Indo-Pacific overturning circulation is critical for understanding the transient response of the global ocean overturning circulation. With a reduction of the AMOC strength in a warming climate, as projected by climate models (Cheng et al. 2013), we show that there is a fast response in the IndoPacific overturning circulation that is characterized by an anomalous northward surface transport and an anomalous southward deep transport. This rapid response in the Indo-Pacific overturning circulation substantially compensates the AMOC changes through an 


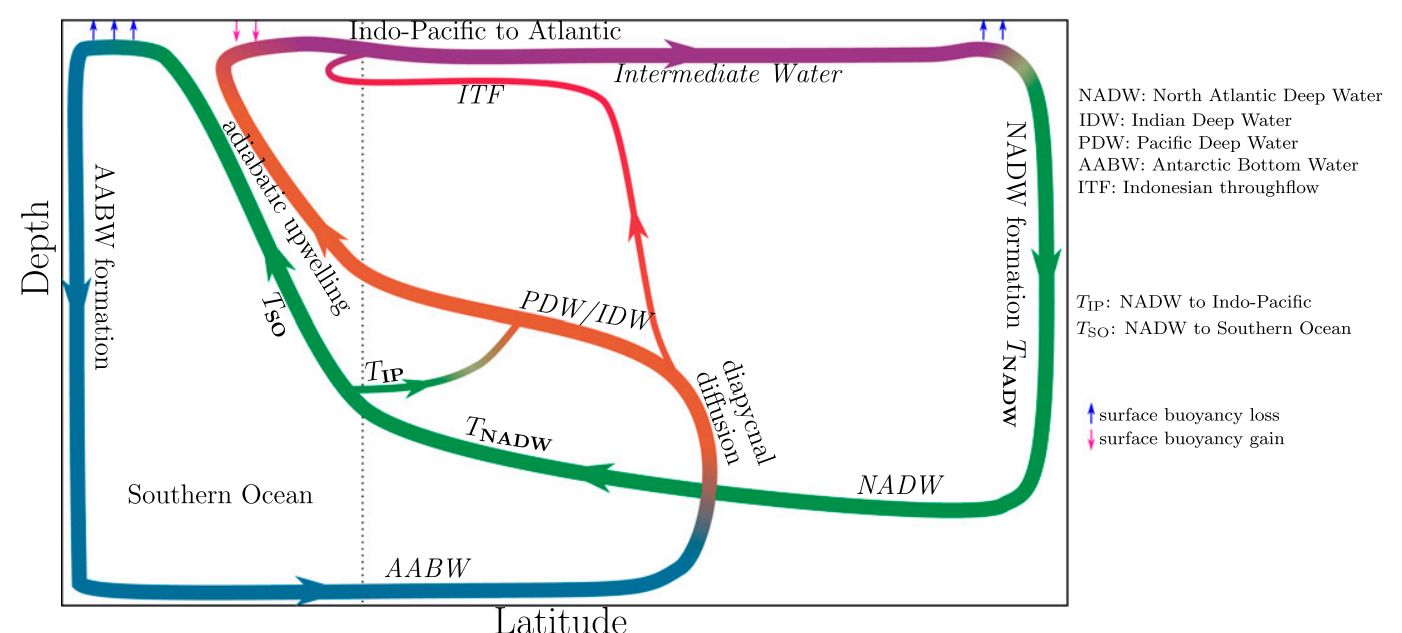

FIG. 1. Two-dimensional (depth-latitude) schematic of the global ocean overturning circulation, adapted from Talley (2013). Colors represent different water masses, and their abbreviations are shown to the right of the figure. Changes in color along pathways indicate watermass transformation. Volume transports are given by the various $T$ terms. The dotted line represents the southern boundary of the basins. The small vertical arrows close to the surface indicate surface buoyancy gain (pink) and loss (blue).

interbasin exchange of water masses such that the AMOC is decoupled from Southern Ocean over time scales up to many decades.

Zonal exchange between Atlantic, Indian, and Pacific basins was first highlighted decades ago in Gordon (1986) as a major pathway of the global ocean overturning circulation. However, more recent studies based on observations estimate that, in the mean state, most NADW upwells along isopycnals in the Southern Ocean (Talley 2013). As such, the global ocean overturning circulation has been depicted in many studies as two separate overturning circulation cells stacked vertically in a two-dimensional depth-latitude space (e.g., Lumpkin and Speer 2007), highlighting the connections between the AMOC and the Southern Ocean. In contrast to this steady-state balance, here we show that interbasin exchange can dominate over Southern Ocean upwelling in the transient adjustment of the global ocean overturning circulation to surface forcing perturbations.

Interbasin exchange between the Atlantic Ocean and the Indo-Pacific Ocean has increasingly been identified as a critical component in determining deep ocean stratification and watermass transformation rates (e.g., Jones and Cessi 2016; Thompson et al. 2016; Ferrari et al. 2017). Recent studies have also highlighted the importance of interbasin exchange in closing heat and buoyancy budgets between the Atlantic and IndoPacific basins (Newsom and Thompson 2018; Holmes et al. 2019). However, to our knowledge, the role of this interbasin exchange in the transient evolution of the global ocean overturning circulation has not previously been investigated. The structure of the paper is as follows. In section 2, we introduce the various ocean and climate models used in this study. We focus on results from a 1.5-layer reduced gravity model to highlight the key dynamics at play in section 3 . We then present results from more comprehensive general circulation model (GCM) simulations in section 4, which show similar features to the reduced gravity model. A discussion of the results is provided in section 5, followed by a brief summary in section 6 .

\section{Model description and method}

Our approach is to use a hierarchy of ocean and climate models. We begin with a highly idealized representation of the global ocean overturning circulation to isolate the key dynamical processes. We then systematically increase the model complexity to determine the robustness of these mechanisms as more processes are included (e.g., Held 2005). The aim throughout is to explore the transient evolution of the global ocean overturning circulation in response to a perturbation to the NADW formation rate. We start with a 1.5-layer reduced gravity model. The reduced gravity model represents the upper northward branch of the AMOC (Fig. 1) and is similar to models used in previous studies (e.g., Johnson and Marshall 2004; Allison et al. 2011; Jones and Cessi 2016). However, this 1.5-layer reduced gravity model omits a number of key components of the global ocean overturning circulation, including a realistic surface forcing in the North Atlantic, which modifies the NADW formation rate, and a realistic surface 

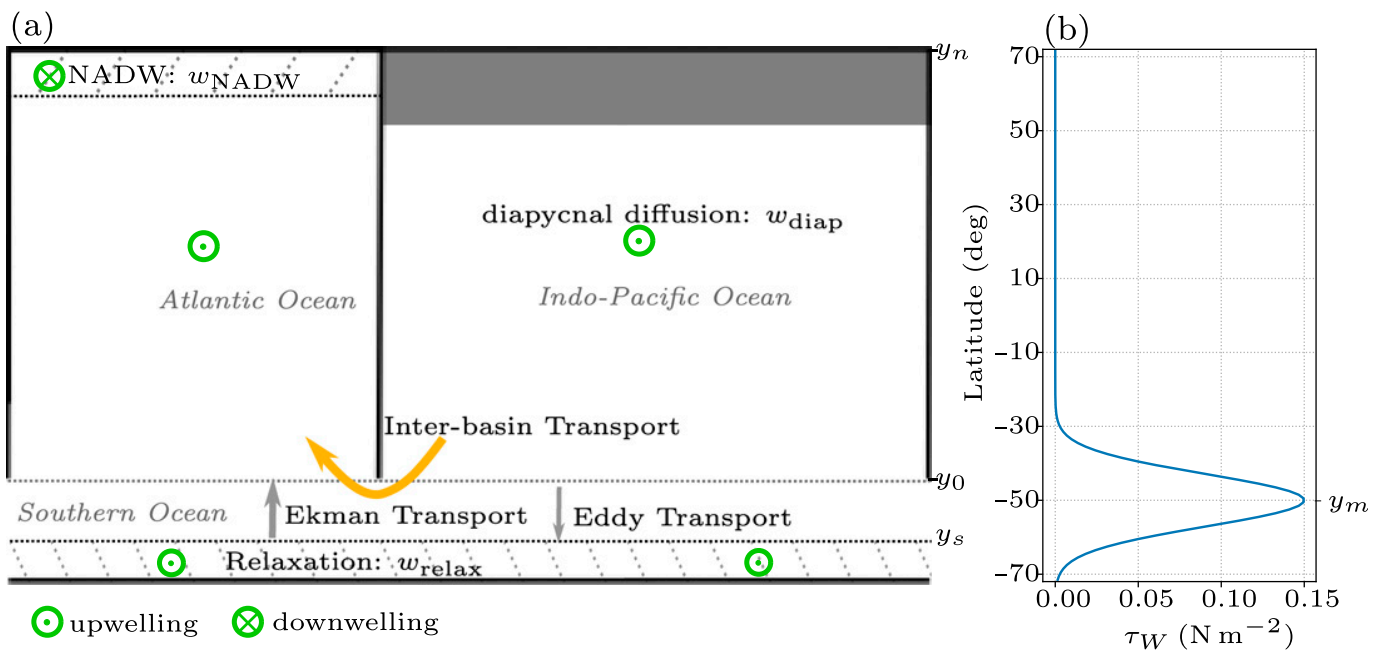

FIG. 2. (a) Schematic of the 1.5-layer reduced gravity model in the Africa-45 configuration (see section 2). The hatched area in the North Atlantic is a region of NADW formation and sinking (downward transport across the interface), $w_{\text {NADW. }}$ This is balanced by transformation elsewhere in the domain (in the basins and the Southern Ocean) that provides a net transport across the interface between the upper and lower layer in the reduced gravity model, $w_{\text {diap }}$ and $w_{\text {relax }}$ (b) The wind stress distribution $\left(\mathrm{N} \mathrm{m}^{-2}\right)$ applied to the reduced gravity model.

forcing in the Southern Ocean, which modifies the Southern Ocean upwelling rate. To address these limitations, we also carry out a set of ocean-only GCM simulations that retain an idealized surface forcing for comparison with the results from the reduced gravity model. Next, in order to explore whether the transient interbasin overturning circulation is a robust feature of the global ocean overturning circulation in a changing climate, we analyze the output from a set of comprehensive GCM simulations under anthropogenic greenhouse gas forcing. As shown below, the ocean's response is qualitatively similar in each of the models, building confidence in the dynamical insights gained from the reduced gravity model.

\section{a. Reduced gravity model}

A schematic of the 1.5-layer reduced gravity model is shown in Fig. 2a. The model domain extends from $72^{\circ} \mathrm{S}$ to $72^{\circ} \mathrm{N}$. It includes a narrow basin $\left(60^{\circ}\right.$ wide $)$, which represents the Atlantic Ocean, a wide basin $\left(120^{\circ}\right.$ wide), which represents the Indo-Pacific Ocean, and a reentrant channel, which represents the Southern Ocean. The two basins are separated by two narrow continents. For simplicity in the following discussion, both continents extend to $45^{\circ} \mathrm{S}\left(y_{0}\right)$ in the reduced gravity model ("Africa- 45 " configuration). The impact of having a more realistic geometry with short and long continents ("Africa-30" configuration) is discussed in section 5 .

The momentum balance in the reduced gravity model is given by

$$
\frac{\partial \mathbf{u}}{\partial t}+\mathbf{u} \cdot \nabla \mathbf{u}+f \mathbf{k} \times \mathbf{u}=-g^{\prime} \nabla h+A_{h} \nabla^{2} \mathbf{u}+\frac{\boldsymbol{\tau}}{\rho_{0} h},
$$

where $\mathbf{u}=(u, v)$ is the horizontal velocity vector, $f\left(\mathrm{~s}^{-1}\right)$ is the latitude-dependent Coriolis parameter, $g^{\prime}=0.01 \mathrm{~m} \mathrm{~s}^{-2}$ is the reduced gravity, $A_{h}=1 \times 10^{4} \mathrm{~m}^{2} \mathrm{~s}^{-1}$ is horizontal viscosity, $\tau\left(\mathrm{N} \mathrm{m}^{-2}\right)$ is the wind stress, $\rho_{0}=$ $1035 \mathrm{~kg} \mathrm{~m}^{-3}$ is the reference density, and $h(\mathrm{~m})$ is the interface depth as a function of space and time.

The wind stress forcing is purely zonal (Fig. 2b),

$$
\tau_{W}=\tau_{0} \exp \left[-\left(y-y_{m}\right)^{2} / L^{2}\right],
$$

where $\tau_{0}=0.15 \mathrm{~N} \mathrm{~m}^{-2}, L=1 \times 10^{3} \mathrm{~km}$, and $y_{m}$ is the meridional location associated with $50^{\circ} \mathrm{S}$. The reduced gravity model has wind stress forcing in the Southern Ocean only for simplicity, but a more realistic wind stress forcing is used in the GCM simulations below. The impact of including a more realistic wind stress forcing in the reduced gravity model is discussed in section 5 .

Mass conservation is given by

$$
\frac{\partial h}{\partial t}+\nabla \cdot(h \mathbf{u})=\nabla \cdot\left(K_{\mathrm{GM}} \nabla h\right)+w_{\text {diap }}+w_{\text {relax }}+w_{\mathrm{NADW}} .
$$

Here, $K_{\mathrm{GM}}=1000 \mathrm{~m}^{2} \mathrm{~s}^{-1}$ is the eddy thickness diffusivity that represents unresolved mesoscale eddies (Gent and McWilliams 1990); $w_{\text {diap }}$ is the diapycnal velocity,

$$
w_{\text {diap }}=\kappa / h,
$$


with $\kappa=2.0 \times 10^{-5} \mathrm{~m}^{2} \mathrm{~s}^{-1}$; $w_{\text {NADw }}$ is a constant velocity specified over the northernmost $5^{\circ}$ latitude in the North Atlantic and represents NADW formation (Fig. 2a); and $w_{\text {relax }}$ is a simplified representation of watermass transformation in the Southern Ocean, which is expressed as a relaxation to a constant interface depth of $h_{c}=10 \mathrm{~m}$,

$$
w_{\text {relax }}=\lambda\left(h_{c}-h\right)
$$

The relaxation is implemented in the southernmost $10^{\circ}$ of latitude with the relaxation time scale $\lambda^{-1}$ increasing northward linearly from 10 days at the southern boundary $\left(72^{\circ} \mathrm{S}\right)$ to 100 days at $62^{\circ} \mathrm{S}$ (Fig. 2a). This relaxation in the Southern Ocean essentially determines the outcropping latitude of the interface. A fast relaxation with $\lambda^{-1}=1 \mathrm{~h}$ is also included wherever the interface depth is less than $h_{c}$ to avoid negative upper layer thickness.

We discretize the model on a $C$ grid with a spherical geometry that has a horizontal resolution of $1^{\circ}$ and integrate using the third-order Adams-Bashforth method. In the control run, we have an NADW formation rate of

$$
T_{\mathrm{NADW}}=-\int_{y_{0}}^{y_{n}} \int_{x_{w}^{A}}^{x_{e}^{A}} w_{\mathrm{NADW}} d x d y=12 \mathrm{~Sv},
$$

where $x_{w}^{A}$ and $x_{e}^{A}$ represent the positions of the western and eastern boundaries of the Atlantic basin. This prescribed downward diapycnal velocity $w_{\text {NADw }}$ shoals the interface and results in a cyclonic gyre circulation in the high-latitude North Atlantic. We prescribe a weaker rate of NADW formation [12 Sv $\left.\left(1 \mathrm{~Sv} \equiv 10^{6} \mathrm{~m}^{3} \mathrm{~s}^{-1}\right)\right]$ in this study, as compared with observations (approximately 20 Sv) (e.g., Talley 2013), to avoid outcropping of the interface in the North Atlantic. We integrate the control run for 3000 years to achieve an approximately steady state, defined as when changes in the global-mean interface depth do not exceed $1 \mathrm{~m}$ per 100 years.

Using the equilibrated control run as initial conditions, we conduct three simulations in which the NADW formation rate $T_{\text {NADW }}$ was abruptly reduced to 10,8 , and $6 \mathrm{~Sv}$. This step change in $T_{\mathrm{NADw}}$ is meant to represent changes in the surface buoyancy forcing in the North Atlantic, which alters the NADW formation rate. The perturbation runs are integrated for 3000 years to ensure an approximately steady-state solution. The adjustment of the overturning following a step change in $T_{\text {NADw }}$ to $8 \mathrm{~Sv}$ is analyzed in section $3 \mathrm{a}$. The steady-state solutions for all three perturbation runs are discussed in section $3 b$.

Previous studies have suggested that the AMOC strength could vary over a variety of time scales, ranging from months to thousands of years (e.g., Zhao and Johns 2014; Sigman et al. 2010). Therefore, in addition to the perturbation runs above, we carry out a separate suite of simulations with time-dependent NADW formation rates,

$$
T_{\text {NADW }}(t)=[12+4 \sin (\omega t)] \mathrm{Sv},
$$

where $\omega$ is the forcing frequency, and $2 \pi / \omega$, the forcing period, ranges from 20 to 2000 years. Each simulation is run through at least two forcing cycles (duration of $4 \pi / \omega$ ), and the last forcing cycle is used for analysis. The dependence of the overturning circulation response on the forcing time scales is discussed in section $3 \mathrm{c}$.

Watermass transformation, which induces a volume flux across the interface between the upper and lower layers of the reduced gravity model, is balanced by a meridional transport in each basin. Integrating Eq. (2) from the southern boundary $y_{0}$ to the northern boundary $y_{n}$ in a given basin (Fig. 2), we have

$$
T^{i}+\int_{y_{0}}^{y_{n}} \int_{x_{w}^{i}}^{x_{e}^{i}}\left(w_{\mathrm{NADW}}+\frac{\kappa}{h}-\frac{\partial h}{\partial t}\right) d x d y=0,
$$

where the superscript $i$ indicates the basin over which the above integration is calculated ( $A$ for Atlantic, $P$ for Indo-Pacific, and $S$ for the greater Southern Ocean region where we integrate around the globe). In Eq. (6), $T^{i}$ is the meridional residual transport across $y_{0}$, integrated from the western boundary $x_{w}^{i}$ to the eastern boundary $x_{e}^{i}$,

$$
T^{i} \equiv \int_{x_{w}^{i}}^{x_{e}^{i}}\left(v h-K_{\mathrm{GM}} \frac{\partial h}{\partial y}\right) d x .
$$

The meridional residual transport $T^{i}$ is a representation of the overturning circulation in the reduced gravity model.

\section{b. Ocean-only GCM}

We use the Massachusetts Institute of Technology General Circulation Model (MITgcm; Marshall et al. 1997) to integrate the hydrostatic primitive equations in a configuration with a coarse resolution $\left(2^{\circ}\right)$ that permits a large number of simulations without incurring excessive computational costs. The model domain is similar to the reduced gravity model (Fig. 3a) with two exceptions: 1) we use a short continent to the east of the Atlantic basin that extends to $30^{\circ} \mathrm{S}$ and a long continent to the west that extends to $45^{\circ} \mathrm{S}$; and 2) we include a submarine ridge in the Southern Ocean to provide bottom form stress that balances the momentum input into 

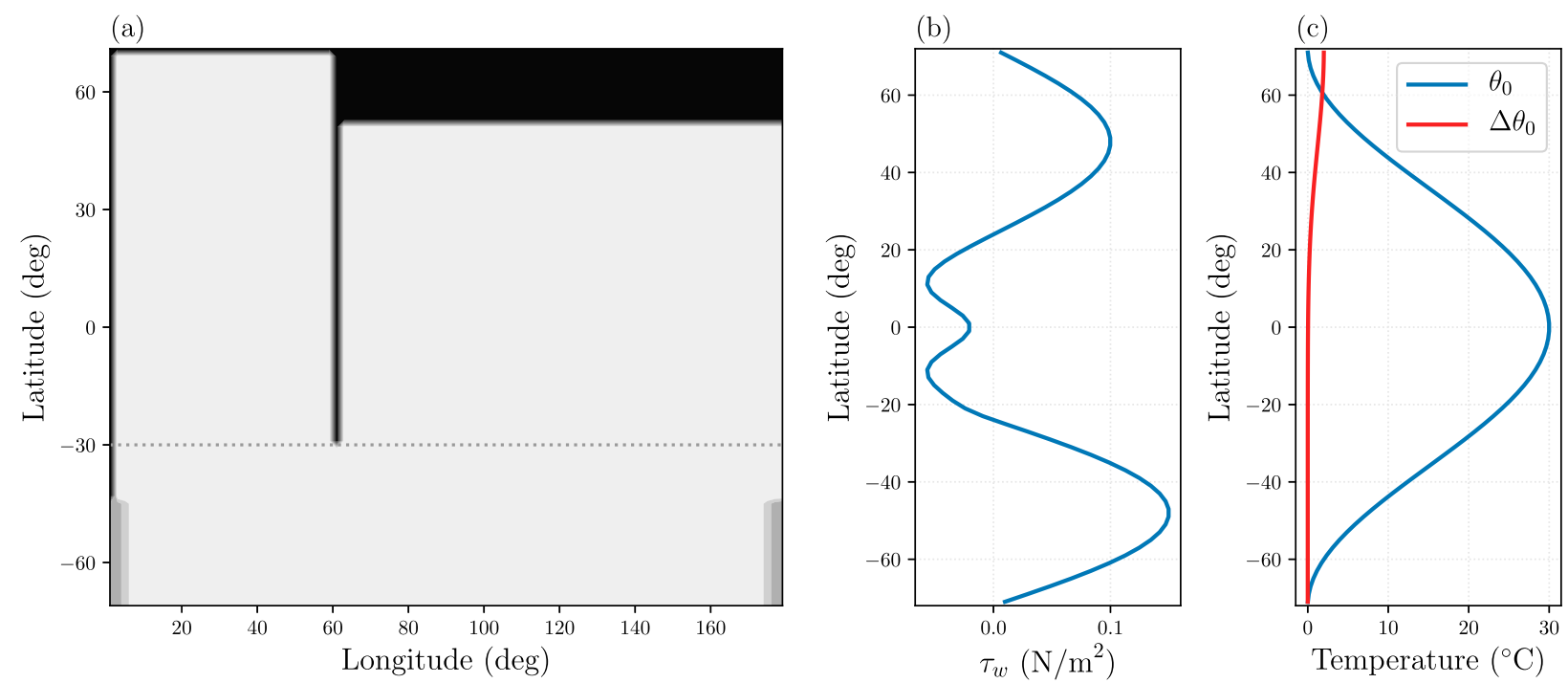

FIG. 3. Model configuration for the MITgcm simulations: (a) Geometry of the model domain. The ocean is $4000 \mathrm{~m}$ deep everywhere except for a 2500 -m-deep submarine sill, indicated by gray shading. The black shading indicates continents. Surface forcing applied to the model: (b) wind stress $\left(\mathrm{N} \mathrm{m}^{-2}\right)$, (c) restoring surface temperature $\theta_{0}$, and surface temperature perturbation field $\Delta \theta_{0}$.

the Antarctic Circumpolar Current from surface wind forcing (Munk and Palmén 1951).

The model domain has 30 vertical layers ranging from $20 \mathrm{~m}$ at the top to $250 \mathrm{~m}$ at the bottom. A vertical diffusivity is implemented that is a function of depth and increases from $2.0 \times 10^{-5} \mathrm{~m}^{2} \mathrm{~s}^{-1}$ at the surface to $1.3 \times$ $10^{-4} \mathrm{~m}^{2} \mathrm{~s}^{-1}$ with a transition depth of $2000 \mathrm{~m}$ (Bryan and Lewis 1979). Similar to the reduced gravity model, unresolved eddies are represented using the skew-flux form of the Gent-McWilliams (GM) parameterization with an eddy thickness diffusivity $K_{\mathrm{GM}}=1000 \mathrm{~m}^{2} \mathrm{~s}^{-1}$. The momentum is dissipated via Laplacian viscosity, biharmonic viscosity, and vertical viscosity with coefficients $A_{h}=1.0 \times 10^{-4} \mathrm{~m}^{2} \mathrm{~s}^{-1}, A_{4}=1.0 \times 10^{12} \mathrm{~m}^{4} \mathrm{~s}^{-1}$, and $A_{v}=1.0 \times 10^{-3} \mathrm{~m}^{2} \mathrm{~s}^{-1}$, respectively. Vertical convection is represented by an implicit vertical diffusion with a diffusivity of $100 \mathrm{~m}^{2} \mathrm{~s}^{-1}$ whenever the stratification is statically unstable.

The model is forced with a zonally uniform wind stress (Fig. 3b). Temperature $\theta$ at the surface is restored to a prescribed temperature profile $\theta_{s}$, defined below, with a relaxation time scale of 20 days. There is no freshwater forcing and thus temperature is the only thermodynamic variable. Similar to the reduced gravity model, the relaxation surface buoyancy boundary condition approximately fixes the outcropping latitude of isopycnals in the Southern Ocean.

In the control run, we use a surface restoring temperature of $\theta_{s}=\theta_{0}(y)$, which is symmetrical about the equator (blue line in Fig. 3c). The control run is integrated for 3000 years, at which point the model reaches an approximate steady state.
To compare with the reduced gravity model simulations, we branch from the end of the control run and perform two sets of perturbation simulations. In the first suite of simulations, the restoring surface temperature in the Atlantic Ocean is abruptly changed by $\Delta \theta_{0}$, which peaks at the northern boundary $72^{\circ} \mathrm{N}$ and decays southward (red line in Fig. 3c), such that

$$
\theta_{s}=\theta_{0}+\Delta \theta_{0}
$$

This perturbation warms the North Atlantic and weakens the AMOC (e.g., Wolfe and Cessi 2011). The magnitude of $\Delta \theta_{0}$ is varied from $0.5^{\circ}$ to $2^{\circ} \mathrm{C}$ at the northern boundary to test the response of the overturning circulation.

In the second suite of simulations, we prescribe a perturbation to the North Atlantic restoring temperature that varies with time,

$$
\theta_{s}=\theta_{0}+\Delta \theta_{0} \sin (\omega t)
$$

where $\Delta \theta_{0}$ (red line in Fig. $3 \mathrm{c}$ ) is $2^{\circ} \mathrm{C}$ at the northern boundary and $2 \pi / \omega$ again is the forcing period, which varies from 20 to 2000 years as for the reduced gravity model.

The meridional overturning circulation streamfunction, defined as a function of latitude and buoyancy, is calculated as

$$
\begin{aligned}
\psi^{i}(y, b)= & -\frac{1}{t_{2}-t_{1}} \int_{t_{1}}^{t_{2}} \int_{x_{w}^{i}}^{x_{e}^{i}} \int_{z_{\mathrm{bot}}}^{0} v_{r}(x, y, z, t) \\
& \times \mathscr{G}\left[b-b^{\prime}(x, y, z, t)\right] d z d x d t,
\end{aligned}
$$



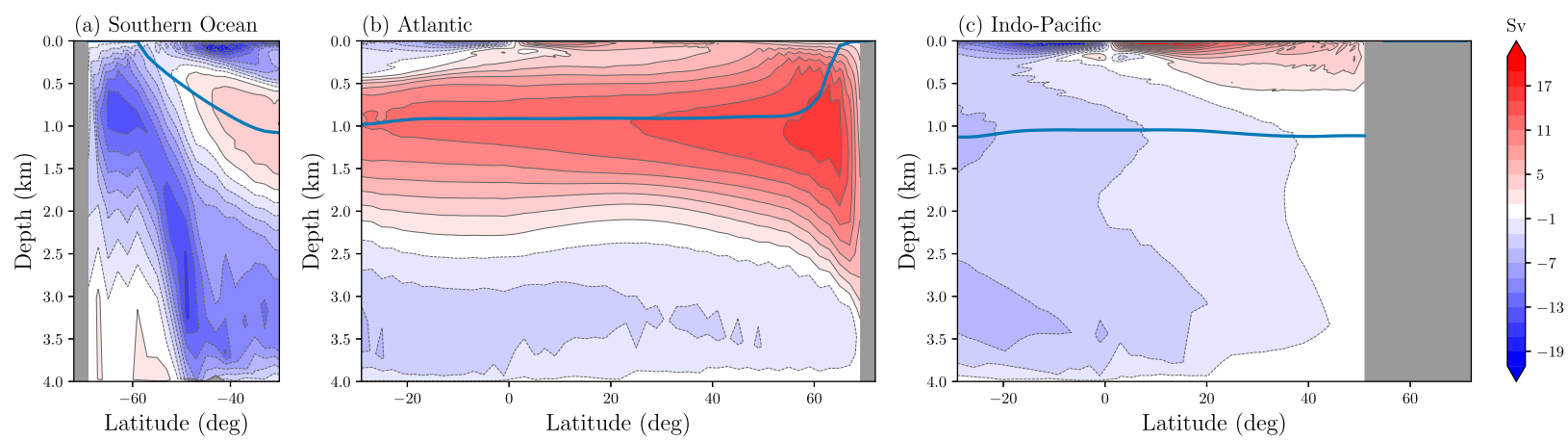

FIG. 4. Meridional overturning circulation streamfunction (Sv) for the MITgcm control run in (a) the Southern Ocean, (b) the Atlantic basin, and (c) the Indo-Pacific basin. The thick blue line represents the isopycnal $b_{m}$ defined in Eq. (12), which serves as an analog to the interface in the reduced gravity model. Contours are plotted at 2-Sv intervals.

where $b$ is buoyancy $\left[b=\alpha\left(\theta-\theta_{\text {ref }}\right)\right]$ with $\alpha$ the thermal expansion coefficient of seawater and $\theta_{\text {ref }}=0^{\circ} \mathrm{C}$, $t_{1}$ and $t_{2}$ define the averaging period, $z_{\text {bot }}$ represents the ocean bottom, $v_{r}$ is the total meridional velocity that includes both the Eulerian-mean flow $(\bar{v})$ and the eddy bolus contribution due to the parameterized eddies, $b^{\prime}$ is the buoyancy field calculated by the model at each location and time step, and $\mathscr{H}\left(b-b^{\prime}\right)$ is the Heaviside step function of $b-b^{\prime}$ such that $\psi^{i}(y, b)$ represents the northward transport above the isopycnal denoted by $b$. The streamfunction $\psi^{i}(y, b)$ is mapped to depth coordinates using the mean depth of each isopycnal (e.g., Sun et al. 2018) (Fig. 4). The meridional overturning circulation in the Atlantic basin is characterized by a clockwise pole-to-pole overturning circulation in the upper $2.5 \mathrm{~km}$ (the AMOC) and an anticlockwise overturning circulation in the abyss (Figs. 4a,b). The clockwise pole-topole adiabatic overturning circulation does not exist in the Indo-Pacific basin (Fig. 4c) because it is only in the Atlantic basin where isopycnals outcrop in both hemispheres (Wolfe and Cessi 2011). Instead, there is an anticlockwise overturning circulation that extends from the bottom to the surface, with two mimima in the streamfunction. The deeper minimum, at a depth near $3 \mathrm{~km}$, is associated with the abyssal overturning circulation, and the shallower minimum near $1 \mathrm{~km}$ arises from the interbasin overturning circulation (Ferrari et al. 2017).

We define the AMOC strength at $30^{\circ} \mathrm{S}\left(y_{1}\right)$ as the maximum value of the overturning circulation streamfunction in the Atlantic Ocean at this meridional position $\left(y_{1}\right)$,

$$
\psi_{m}^{A} \equiv \max \left[\psi^{A}\left(y_{1}, b\right)\right]
$$

To highlight interbasin exchange, we focus on the AMOC strength at $30^{\circ} \mathrm{S}$ instead of in the North Atlantic, for example at $30^{\circ} \mathrm{N}$, which is more commonly used in the literature (e.g., Cheng et al. 2013). However, the AMOC streamfunction varies coherently throughout the Atlantic basin over the time scales considered in this study (e.g., Zhang 2010). To allow comparison with the reduced gravity model, we define an isopycnal $b_{m}$ that is the analog to the interface in the reduced gravity model. The isopycnal $b_{m}$ satisfies

$$
\psi^{A}\left(y_{1}, b_{m}\right)=\psi_{m}^{A}
$$

in the control run, and it approximately separates the northward upper branch from the southward lower branch of the AMOC (thick blue line in Fig. 4b). The analogy to the reduced gravity model's meridional residual transport can be calculated in the GCM simulations as

$$
T^{i}=\psi^{i}\left(y_{1}, b_{m}\right)-\psi^{i}\left(y_{1}, b_{\max }\right),
$$

where $b_{\max }$ is the maximum buoyancy at the meridional position $y_{1}$. The last term in Eq. (13), $\psi^{i}\left(y_{1}, b_{\max }\right)$, is equivalent to the meridional barotropic transport across $y_{1}$; this term may be nonzero if the model is in a transient state or if there is a transport through the northern boundary (e.g., the Bering Strait). The overturning circulation may move vertically in isopycnal coordinates in response to a surface forcing perturbation, such that the transport $T^{i}$ is only an approximation to the overturning circulation strength.

\section{c. Climate model simulations}

As the climate warms, climate models consistently predict the AMOC to weaken in the twenty-first century (Cheng et al. 2013). To evaluate the role of interbasin exchange in the climate system, we use the NCAR Community Earth System Model (CESM) Large Ensemble (Kay et al. 2015) during years 2006-2100. The CESM 
Large Ensemble contains 40 ensemble members that simulate the climate trajectories over 1920-2100 under historical (1920-2005) and representative concentration pathway 8.5 emission scenario (2006-2100). These members share the same model physics and forcing; they are branched from the same control run on 1 January 1920, with random round-off level differences being applied to their initial air temperature field (Kay et al. 2015).

With increasing atmospheric greenhouse gas concentrations in the CESM simulations of the twenty-first century, the surface ocean warms and freshens in the North Atlantic, leading to a stronger near-surface density stratification and thus reducing NADW formation (e.g., Gregory et al. 2005). In contrast to the abrupt NADW formation reduction in the reduced gravity model and MITgcm simulations, the AMOC gradually weakens during the twenty-first century simulations, as discussed in section 4. Additionally, the surface buoyancy flux in the CESM simulations is dominated by the freshwater flux in the Southern Ocean (e.g., Sun et al. 2016), whereas the reduced gravity model and MITgcm use a relaxation boundary condition which is more suitable to represent surface heat flux (Haney 1971). The impact of using different types of surface buoyancy flux conditions on the results is discussed in section 5 .

In section 4, we examine both the global ocean overturning circulation and the associated meridional heat transport in the CESM simulations. We define the meridional overturning circulation streamfunction and the meridional transport in the same way as in the MITgcm simulations [Eqs. (10) and (13)], except that the isopycnal interface $b_{m}$ is defined with the AMOC streamfunction at year 2006 and the buoyancy is defined as

$$
b=-\frac{g}{\rho_{0}}\left(\sigma_{2}-\rho_{0}\right),
$$

where $g$ is the gravitational parameter and $\sigma_{2}$ is the potential density referenced to 2000 dbar. The meridional heat transport averaged between a time period from $t_{1}$ to $t_{2}$ due to the residual flow $v_{r}$ at a meridional location $y$ is calculated as

$$
\begin{aligned}
Q^{i}(y)= & \frac{1}{t_{2}-t_{1}} \int_{t_{1}}^{t_{2}} \int_{z_{\mathrm{bot}}}^{0} \int_{x_{w}^{i}}^{x_{e}^{i}} v_{r}(x, y, z, t) \\
& \times\left[\theta(x, y, z, t)-\theta_{\mathrm{ref}}\right] d x d z d t,
\end{aligned}
$$

where $\theta_{\text {ref }}=0^{\circ} \mathrm{C}$ is the reference temperature. We can separate the contribution that is related to the Eulerianmean flow $(\bar{v})$ as

$$
\begin{aligned}
\bar{Q}^{i}(y)= & \frac{1}{t_{2}-t_{1}} \int_{t_{1}}^{t_{2}} \int_{z_{\mathrm{bot}}}^{0} \int_{x_{w}^{i}}^{x_{e}^{i}} \bar{v}_{r}(x, y, z, t) \\
& \times\left[\theta(x, y, z, t)-\theta_{\mathrm{ref}}\right] d x d z d t .
\end{aligned}
$$

\section{Response in the reduced gravity model}

In this section, we show that the interbasin transport and Southern Ocean overturning circulation respond on two distinct time scales. For AMOC responses over decadal and centennial time scales, the meridional transport in the Indo-Pacific Ocean largely compensates changes in the Atlantic Ocean overturning.

To understand the overturning circulation responses on different time scales, we now partition the residual transport across the southern boundary of the basins [Eq. (7)] into processes with distinct characteristic time scales. Consider the circulation response on a time scale $T \gg 1$ day and a length scale $L \sim 1000 \mathrm{~km}$ for a characteristic velocity $U \sim 0.01 \mathrm{~m} \mathrm{~s}^{-1}$, such that the Rossby number is

$$
\mathrm{Ro} \equiv \frac{U}{f L} \sim \frac{1}{f T} \ll 1
$$

and the Ekman number is

$$
\mathrm{Ek} \equiv \frac{A_{h}}{f L^{2}} \ll 1
$$

In this regime, the tendency term, nonlinear advection, and horizontal viscosity are all small terms in the momentum balance [Eq. (1)], and the zonal component, multiplied by $h$, reduces to

$$
-f h v \approx-\frac{g^{\prime}}{2} \frac{\partial h^{2}}{\partial x}+\frac{\tau_{W}}{\rho_{0}} .
$$

Substituting $v h$ from Eq. (16) into Eq. (7), we can write the residual transport across the southern boundary $y_{0}$ as

$$
\begin{aligned}
T^{i} & \approx \int_{x_{w}^{i}}^{x_{e}^{i}}\left(\frac{g^{\prime}}{2 f_{0}} \frac{\partial h^{2}}{\partial x}-\frac{\tau_{W}}{\rho_{0} f_{0}}-K_{\mathrm{GM}} \frac{\partial h}{\partial y}\right) d x \\
& \approx \underbrace{\frac{g^{\prime}}{2 f_{0}}\left[\left(h_{e}^{i}\right)^{2}-\left(h_{w}^{i}\right)^{2}\right]}_{T_{G}^{i}}+\underbrace{\frac{-\tau_{W}\left(x_{e}^{i}-x_{w}^{i}\right)}{\rho_{0} f_{0}}}_{T_{W}^{i}} \\
& +\underbrace{\int_{x_{w}^{i}}^{x_{e}^{i}}-K_{\mathrm{GM}} \frac{\partial h}{\partial y} d x}_{T_{E}^{i}},
\end{aligned}
$$


where the superscript $i$ again indicates the basin in which the residual transport is calculated, $f_{0}$ is the Coriolis parameter at $y_{0}, T_{G}^{i}$ represents a meridional geostrophic transport that is determined by the interface depths at the eastern boundary $\left(h_{e}^{i}\right)$ and the western boundary $\left(h_{w}^{i}\right)$ of the basin, $T_{W}^{i}$ represents the northward Ekman transport due to the westerly wind stress $\tau_{W}$, and $T_{E}^{i}$ represents the parameterized meridional eddy transport. Using the mean isopycnal slope in the Southern Ocean to approximate $\partial h / \partial y$, we can write the meridional eddy transport as

$$
T_{E}^{i} \approx-K_{\mathrm{GM}} \frac{h_{0}^{i}}{L_{y}}\left(x_{e}^{i}-x_{w}^{i}\right),
$$

where $h_{0}^{i}$ is the interface depth zonally averaged at $y_{0}$ in the basin that is represented by the superscript $i$, and $L_{y}=y_{0}-y_{s}$ is the meridional distance from the northern boundary of the Southern Ocean relaxation region $y_{s}$ to $y_{0}$ (see Fig. 2).

In the simplified case where both continents have their southern boundary at the same latitude, the interface depth on the meridional boundaries at $y_{0}$ satisfies

$$
h_{e}^{P}=h_{w}^{A}, \quad h_{w}^{P}=h_{e}^{A} .
$$

Thus, the meridional geostrophic transports in the Atlantic and the Indo-Pacific basins at $y_{0}$ are of equal magnitude but opposite sign:

$$
T_{G}^{A}+T_{G}^{P}=0 .
$$

The meridional geostrophic transport components $\left(T_{G}^{P}\right.$ and $T_{G}^{A}$ ) represent an interbasin exchange between the Atlantic and the Indo-Pacific basins (e.g., Jones and Cessi 2016; Thompson et al. 2016). In the idealized Southern Ocean (Fig. 2a), the net meridional geostrophic transport is zero due to the lack of any meridional boundary to support a zonal pressure gradient [Eq. (20)]. Instead, the meridional residual transport at latitude $y_{0}$ in the Southern Ocean $\left(T^{S}\right)$ can be written as

$$
T^{S} \approx T_{W}^{S}+T_{E}^{S} \approx-\frac{\tau_{W} L_{x}}{\rho_{0} f_{0}}-\frac{K_{\mathrm{GM}} h_{0}^{S} L_{x}}{L_{y}},
$$

where we approximate the interface slope as $-h_{0}^{S} / L_{y}$ and $L_{x}=x_{e}^{P}-x_{w}^{A}$ is the zonal width of the Southern Ocean at $y_{0}$.

\section{a. Transient response to a step change in NADW formation}

A step change that reduces the NADW formation rate in the reduced gravity model, with other forcing fields kept constant, leads to a reduction in the residual transport at the southern boundary of the Atlantic basin $T^{A}$. Because the wind stress is constant, changes to $T^{A}$ must be caused by changes in the meridional geostrophic transport $T_{G}^{A}$ or the eddy transport $T_{E}^{A}$ [Eq. (17)]. In this section, we show that $T^{A}$ has both a fast and a slow response that are related to $T_{G}^{A}$ and $T_{E}^{A}$, respectively.

The reduction in NADW formation drives an anomalous gyre circulation in the North Atlantic that extends from the northern boundary to the equator (Fig. 5) (cf. Goldsbrough 1933). The anomalous circulation is characterized by a deepening of the interface on the western boundary relative to the eastern boundary in the North Atlantic, corresponding to a southward geostrophic transport anomaly. The interface deepening signal propagates southward along the western boundary of the North Atlantic via coastal Kelvin waves and then propagates eastward along the equator via equatorial Kelvin waves, with a phase speed of approximately $c_{K}=\left(g^{\prime} h\right)^{1 / 2} \approx 2.8 \mathrm{~m} \mathrm{~s}^{-1}$ (gray dashed line in Fig. 5b). After reaching the eastern boundary ("C" $\mathrm{C}$ " in Fig. 5a), the interface anomaly excites an equatorial Rossby wave that propagates westward at a speed characterized by the long wave approximation, $c_{R}=$ $c_{K} / 3 \approx 0.9 \mathrm{~m} \mathrm{~s}^{-1}$ (gray dashed line in Fig. 5b) (Gill 1982). After the long equatorial Rossby wave arrives at the western boundary in approximately 3 months, a standing wave mode is established and the interface depth along the equator deepens uniformly with time as the North Atlantic gyre circulation adjusts (Fig. 5b).

The interface deepening on the eastern boundary at the equator also excites southward-propagating Kelvin waves along the eastern boundary of the South Atlantic (from " $C$ " to " $D$ " in Fig. 5). These waves appear in the Hovmöller diagram to be slower than predicted due to the decaying amplitude of Kelvin waves, which radiate energy into the interior via westward propagating Rossby waves (Johnson and Marshall 2002). The southward Kelvin wave arrives at the southern tip of Africa ("D" in Fig. 5a) after 1 month and generates a change in the zonal interface depth difference between the western and eastern boundaries across the Atlantic basin at $y_{0}$ (Fig. 5c). This modification to the zonal interface depth difference is linked to a southward geostrophic transport anomaly in the Atlantic basin [Eq. (17)]. Meanwhile, the Indo-Pacific basin responds with a northward geostrophic transport anomaly, which opposes the Atlantic changes [Eq. (20)]. This response in the geostrophic transport at $y_{0}$ first occurs a couple months after the NADW perturbation and peaks after 50 years (Fig. $5 \mathrm{c}$ ). The 50 -yr time scale is associated with the adjustment of the gyre circulation in the North Atlantic (Fig. 5a). Note that these time scales are sensitive to the selected model parameters, such as the 

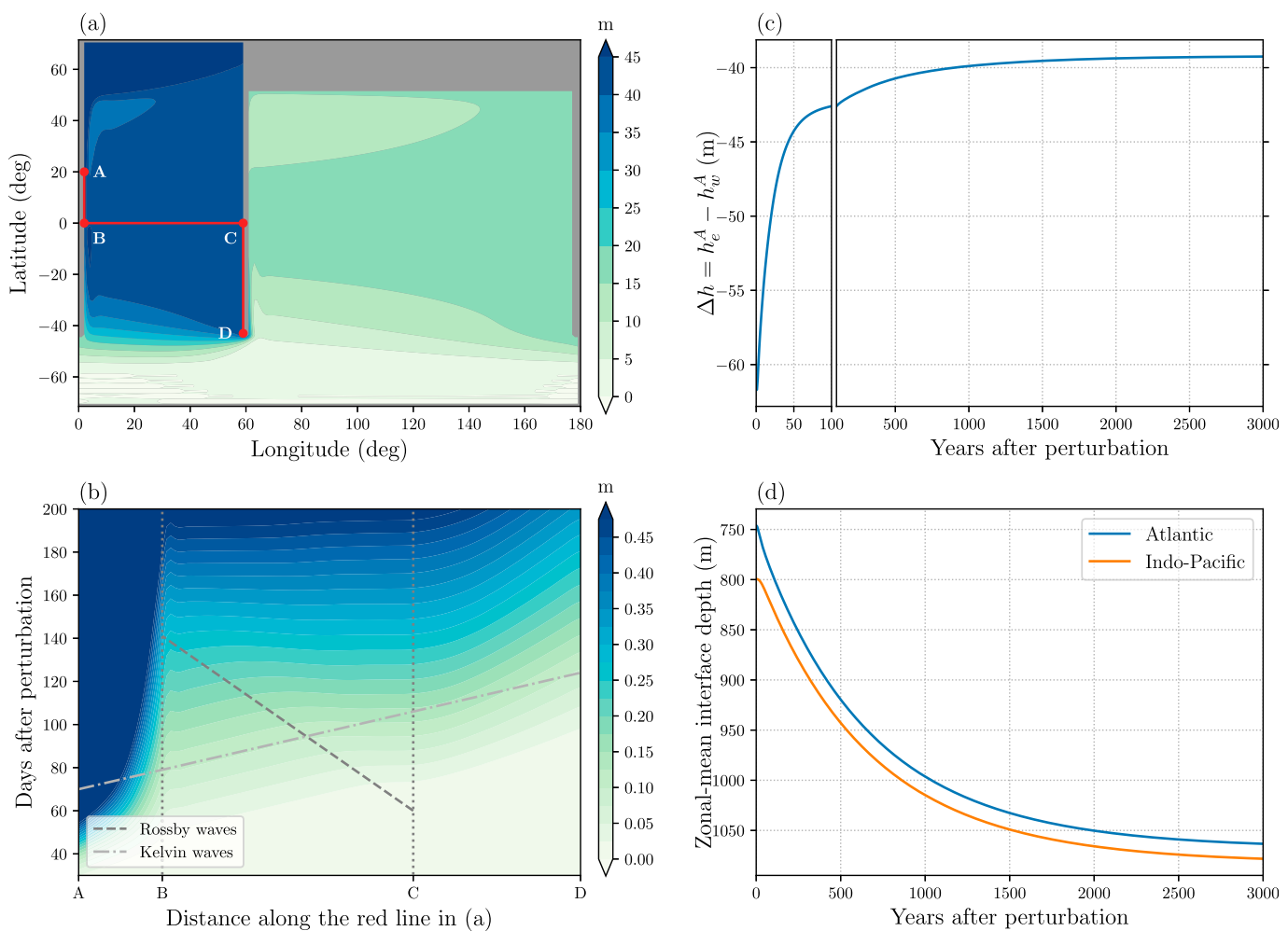

FIG. 5. Response of the interface depth to a $-4-\mathrm{Sv}$ step change in the NADW formation rate in the reduced gravity model: (a) Change in the interface depth 50 years after the NADW formation reduction (m). (b) Hovmöller diagram of the interface depth anomaly $\delta h(\mathrm{~m})$ along the red line in (a). (c) Time series of the zonal interface depth difference $(\mathrm{m})$ between the eastern and western boundaries of the Atlantic basin at $45^{\circ} \mathrm{S}, \Delta h=h_{e}^{A}-h_{w}^{A}$. Note the change in temporal discretization to highlight the fast response during the first 100 years. (d) Time series of the zonally averaged interface depth, along $45^{\circ} \mathrm{S}$ in the Atlantic basin $\left(h_{0}^{A}\right.$; blue curve $)$ and the Indo-Pacific basin $\left(h_{0}^{P}\right.$; orange curve). In (b), we use a gray dash-dotted line to indicate the phase speed of Kelvin waves and a gray dashed line to indicate the westward propagation speed of equatorial Rossby waves. The Kelvin wave speed is estimated to be $c_{K}=\left(g^{\prime} h\right)^{1 / 2} \approx 2.8 \mathrm{~m} \mathrm{~s}^{-1}$, and the equatorial Rossby wave speed is estimated to be $c_{R}=c_{K} / 3 \approx 0.9 \mathrm{~m} \mathrm{~s}^{-1}$ (Gill 1982).

reduced gravity, which determines the Kelvin and Rossby wave propagation speed and influences the gyre adjustment.

Interface deepening on the eastern boundary also radiates into the interior via westward-propagating Rossby waves on a decadal time scale. Thus, interface displacements on the eastern boundary are indicative of the zonally averaged changes in the interface depth of each basin. While the interface deepens in both basins over the first 50 years after the NADW perturbation, the average interface displacement is $30 \mathrm{~m}$ in the Atlantic but $10 \mathrm{~m}$ in the Indo-Pacific (Fig. 5a).

The downward displacement of the interface depth also leads to an enhancement of the southward eddy transport, which is proportional to the zonal-mean interface depth at $y_{0}$ [Eq. (18)]. Assuming that the zonalmean interface depth $h_{0}^{A}$ and the zonal interface depth difference $\Delta h=h_{e}^{A}-h_{w}^{A}$ change by the same order of magnitude during the first 50 years of adjustment
(Figs. 5c,d), i.e., $\delta h_{0}^{A} \sim \delta h_{e}^{A}-\delta h_{w}^{A}$, we can estimate the relative importance of the eddy transport response $\left(\delta T_{E}^{A}\right)$ as compared with the geostrophic transport response $\left(\delta T_{G}^{A}\right)$ as

$$
\frac{\delta T_{E}^{A}}{\delta T_{G}^{A}} \approx \frac{K_{\mathrm{GM}}\left(x_{e}^{A}-x_{w}^{A}\right) / L_{y}}{\left(g^{\prime} / f_{0}\right) h_{0}^{A}},
$$

recalling that the meridional geostrophic transport is

$$
T_{G}^{A}=\frac{g^{\prime}}{2 f_{0}}\left[\left(h_{e}^{A}\right)^{2}-\left(h_{w}^{A}\right)^{2}\right]
$$

and thus the change in $T_{G}^{A}$ can be approximated as

$$
\delta T_{G}^{A} \approx \frac{g^{\prime}}{f_{0}} h_{0}^{A}\left(\delta h_{e}^{A}-\delta h_{w}^{A}\right) .
$$

Applying the zonal-mean interface depth $h_{0}^{A} \approx 750 \mathrm{~m}$ from the control run, this yields $\delta T_{E}^{A} / \delta T_{G}^{A} \approx 0.02$. 
Reduced gravity model
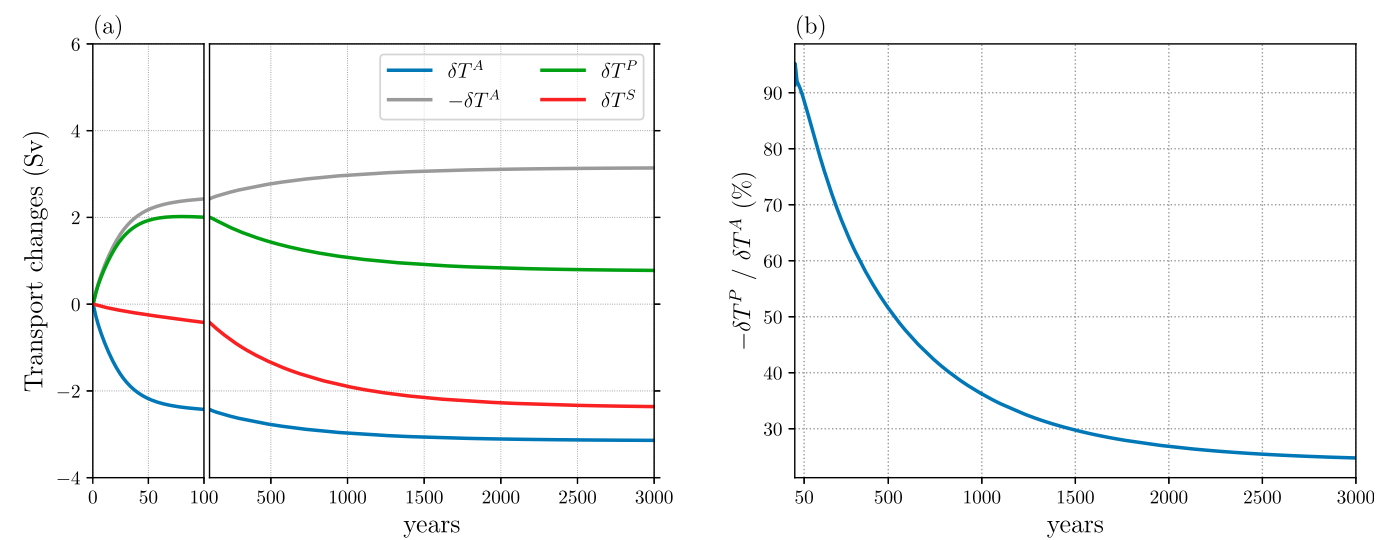

MITgcm
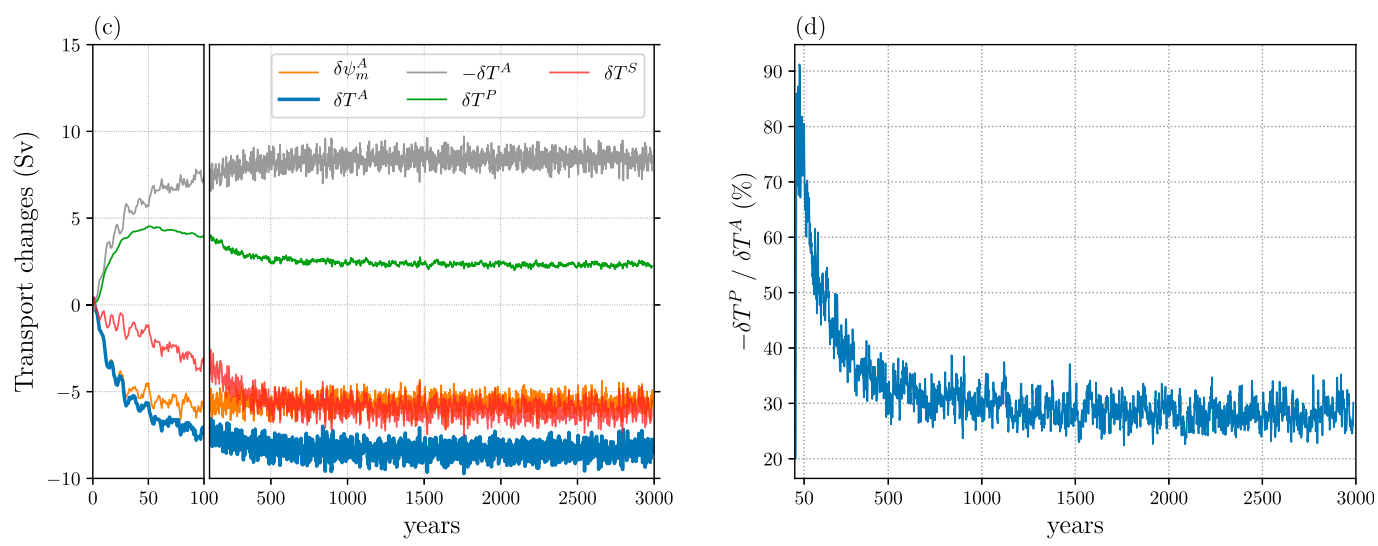

FIG. 6. Response of the overturning circulation to a step change in the NADW formation in (top) the reduced gravity model and (bottom) the MITgcm simulations: (a) Time series of the residual transport (Sv) at the southern boundary of the basins to a step change that reduces the NADW formation by $4 \mathrm{~Sv}$. (b) Time series of the ratio $-\delta T^{P} / \delta T^{A}$ from (a). (c) Time series of the residual transport (Sv) at the southern boundary of the basins $\left(30^{\circ} \mathrm{S}\right)$ to an abrupt $2^{\circ} \mathrm{C}$ warming in the North Atlantic; i.e., $\Delta \theta_{0}$ is $2^{\circ} \mathrm{C}$ at the northern boundary. (d) Time series of the ratio $-\delta T^{P} / \delta T^{A}$ from (c). The first 100 years is enlarged to show the fast response in (a) and (c). In all panels, $\delta T$ represents the transport anomaly from the equilibrated state of the control run.

In other words, modifications to the meridional residual transport across $y_{0}$ in response to a NADW formation perturbation is dominated by changes in the geostrophic transport within the first 50 years. A similar conclusion can be reached for the Indo-Pacific basin, such that the residual transports in the Atlantic basin $T^{A}$ and the Indo-Pacific basin $T^{P}$ respond with similar magnitudes but opposite signs during the first 50 years (Fig. 6a), leaving the Southern Ocean transport largely unchanged. We quantify this interbasin compensation between the Atlantic and the Indo-Pacific as $-\delta T^{A} / \delta T^{P}$, and the compensation level is close to $90 \%$ during the first 50 years in the reduced gravity model simulations (Fig. 6b).

Following the fast response in the first 50 years, the interface depth continues to increase due to an imbalance between the NADW formation and the Southern
Ocean residual transport, which stays roughly constant during the first 50 years (Fig. 6). The continuous deepening of the interface steepens the isopycnal slope across the Southern Ocean. This results in a long-term enhancement of the southward eddy transport across the southern boundary of the basins $y_{0}$, leading to a reduced northward transport anomaly in the Indo-Pacific basin after 100 years (Fig. 6a). Combining Eqs. (6) and (21) gives the evolution of the global-mean interface depth $h_{0}$, which we use to approximate the zonal-mean interface depth at $y_{0}$ :

$$
S_{0} \frac{\partial h_{0}}{\partial t} \approx-T_{\mathrm{NADW}}+\frac{\kappa S_{0}}{h_{0}}-\frac{\tau_{W} L_{x}}{\rho_{0} f_{0}}-\frac{K_{\mathrm{GM}} h_{0} L_{x}}{L_{y}},
$$

where $S_{0}$ is the surface area of the global ocean north of $y_{0}$, and we have approximated the diapycnal velocity 
using $h_{0}$ in Eq. (3). Following a perturbation to $T_{\text {NADW }}$ and assuming a constant wind stress, the response time scale of $h_{0}$ is determined by two processes: 1 ) diapycnal diffusion,

$$
t_{\text {diff }} \sim \frac{h_{0}^{2}}{\kappa},
$$

and 2) Southern Ocean eddies,

$$
t_{\text {eddy }} \sim \frac{S_{0} L_{y}}{K_{\mathrm{GM}} L_{x}} .
$$

Using $S_{0}=1.9 \times 10^{14} \mathrm{~m}^{2}, h_{0}=800 \mathrm{~m}, \kappa=2.0 \times$ $10^{-5} \mathrm{~m}^{2} \mathrm{~s}^{-1}, L_{y}=1.5 \times 10^{6} \mathrm{~m}, K_{\mathrm{GM}}=1000 \mathrm{~m}^{2} \mathrm{~s}^{-1}$, and $L_{x}=1.6 \times 10^{7} \mathrm{~m}$ from the model implies $t_{\text {diff }} \sim 1000$ years and $t_{\text {eddy }} \sim 600$ years. This suggests that the eddy transport responds on multicentennial to millennial time scales that are determined by diffusion processes. Note that the estimate of the eddy transport response time scale depends on the magnitude of the constant eddy thickness diffusivity $K_{\mathrm{GM}}$ as well as the formulation of the eddy parameterization (e.g., Jones et al. 2011). The estimate in Eq. (27) also assumes a constant outcropping position of the interface in the Southern Ocean. Thompson et al. (2019) used a box model with fixed Southern Ocean surface buoyancy fluxes, which allows the outcropping position to move meridionally, and they found a shorter but still multicentennial time scale for adjustment of the isopycnal depth. The impact of having a fixed surface buoyancy is discussed in section 5 .

Enhancement of the meridional eddy transport leads to a gradual weakening of the interbasin compensation (Fig. 6b). During this slow response, changes in the zonal-mean interface depth at $y_{0}$ are approximately the same across the two basins, i.e., $\delta h_{0}^{A} \approx \delta h_{0}^{P}$ (Fig. $5 \mathrm{~d}$ ). Thus, we can relate the meridional eddy transport across $y_{0}$ in the Atlantic and the Indo-Pacific basin as

$$
\delta T_{E}^{P} \approx 2 \delta T_{E}^{A},
$$

since the Indo-Pacific basin is 2 times as wide as the Atlantic. With Eqs. (17) and (20), we can write the interbasin compensation as

$$
\frac{-\delta T^{P}}{\delta T^{A}} \approx \frac{T_{G}^{A}-2 T_{E}^{A}}{T_{G}^{A}+T_{E}^{A}}=1-\frac{3}{\delta T_{G}^{A} / \delta T_{E}^{A}+1} .
$$

This relationship predicts that the interbasin compensation decreases as the meridional eddy transport increases.

\section{b. Equilibrium response to changes in NADW formation}

Next we consider the equilibrium response of the model to a change in NADW formation $\delta T_{\mathrm{NADW}}$.
By definition, the change in the Southern Ocean residual transport at $y_{0}$ can be written as $\delta T^{S}=\delta T^{A}+\delta T^{P}$, and the interbasin compensation between the Atlantic and the Indo-Pacific can be written as

$$
-\frac{\delta T^{P}}{\delta T^{A}}=-\frac{\delta T^{P}}{\delta T^{S}-\delta T^{P}}=\frac{1}{1-\delta T^{S} / \delta T^{P}} .
$$

In steady state, $\partial h / \partial t=0$, and the meridional residual transport across the southern boundary of the IndoPacific basin [Eq. (6)] changes by

$$
\delta T^{P}=-\delta T_{d}^{P},
$$

with $T_{d}^{P}$ defined as

$$
T_{d}^{P} \equiv \int_{y_{0}}^{y_{n}} \int_{x_{w}^{P}}^{x_{e}^{P}} \frac{\kappa}{h} d x d y \approx \frac{\kappa S^{P}}{h_{0}},
$$

where $S^{P}$ is the surface area in the Indo-Pacific north of $y_{0}$ and $T_{d}^{P}$ represents the diapycnal watermass transformation rate in the Indo-Pacific basin, which is approximated using the global mean interface depth $h_{0}$. Therefore, we can write

$$
\delta T^{P}=-\delta T_{d}^{P} \approx \frac{\kappa S^{P}}{h_{0}^{2}} \delta h_{0},
$$

where the approximation uses a first-order Taylor expansion of $T_{d}^{P}$ relative to the control run.

With a constant wind stress forcing, the Southern Ocean residual transport [Eq. (21)] changes by

$$
\delta T^{S} \approx-\frac{K_{\mathrm{GM}} L_{x}}{L_{y}} \delta h_{0},
$$

where we use the global-mean interface depth $h_{0}$ to approximate the zonal-mean interface depth at $y_{0}$.

Combining Eqs. (30), (32), and (34) together, we have the interbasin compensation in steady state as

$$
\frac{-\delta T^{P}}{\delta T^{A}}=\left(1+\frac{\delta T^{S}}{\delta T_{d}^{P}}\right)^{-1} \approx\left(1+\frac{K_{\mathrm{GM}} L_{x} h_{0}^{2}}{\kappa L_{y} S^{P}}\right)^{-1} .
$$

Therefore, the interbasin compensation in steady state can be estimated from the control run using the diapycnal transformation rate in the Indo-Pacific basin and the meridional eddy transport in the Southern Ocean. This further suggests that a change in the watermass transformation rate in the Indo-Pacific basin can modify the AMOC strength through an interbasin transport, without changing the Southern Ocean overturning circulation (e.g., Newsom and Thompson 2018). In the adiabatic limit, $\delta T_{d}^{P}=0$, the interbasin compensation 

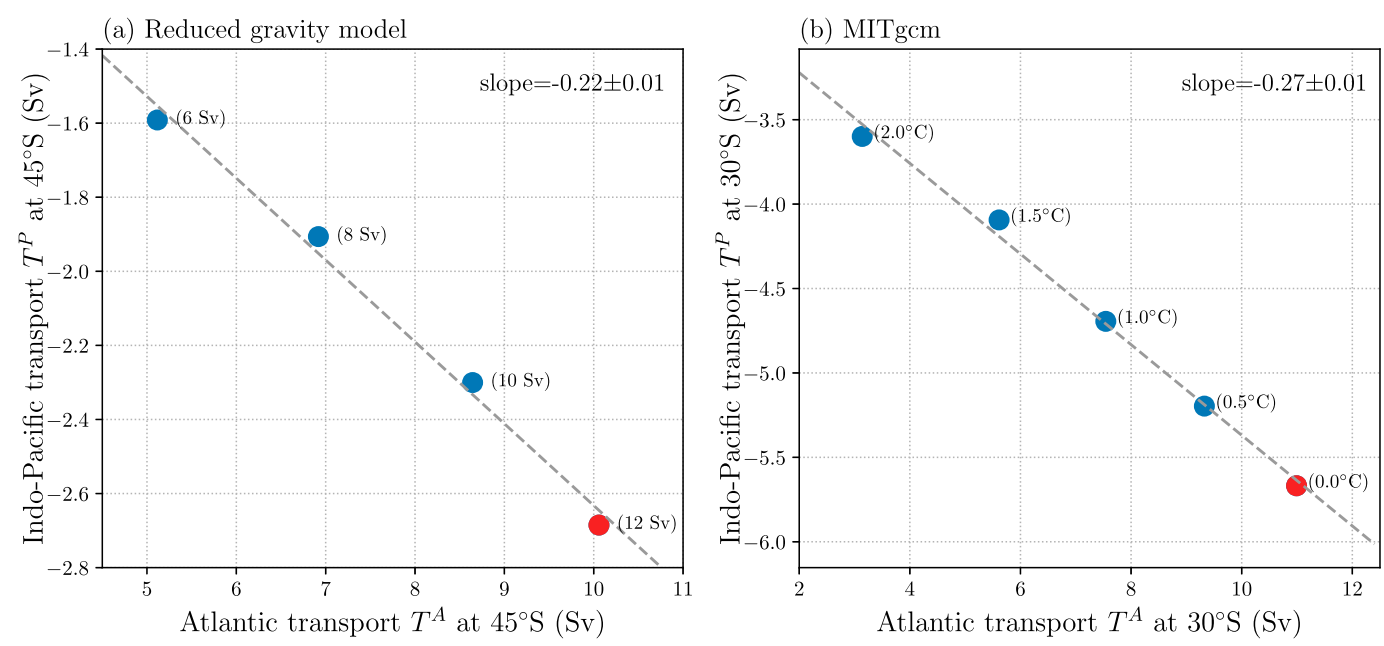

FIG. 7. Equilibrium response of the overturning circulation to NADW formation changes in (a) the reduced gravity model and (b) the MITgcm simulations. The red dot represents the control run, and each blue dot represents a perturbation run. The NADW formation rate is indicated in (a) for the reduced gravity model in parentheses next to each plotted point. The magnitude of the surface temperature perturbation $\Delta \theta_{0}$ is indicated in (b) for the MITgcm simulations. The slope of the Indo-Pacific residual transport vs the Atlantic residual transport, which is calculated using ordinary least squares regression, is included in each panel.

approaches zero in steady state, and the Southern Ocean overturning circulation must experience the same change as the AMOC.

Using $S^{P}=1.2 \times 10^{14} \mathrm{~m}^{2}, K_{\mathrm{GM}}=1000 \mathrm{~m}^{2} \mathrm{~s}^{-1}, \kappa=$ $2.0 \times 10^{-5} \mathrm{~m}^{2} \mathrm{~s}^{-1}, L_{x}=1.6 \times 10^{7} \mathrm{~m}, L_{y}=1.5 \times 10^{6} \mathrm{~m}$, and $h_{0}=800 \mathrm{~m}$ from the control run, we estimate the interbasin compensation level in steady state to be approximately $26 \%$, i.e., the Indo-Pacific can compensate $26 \%$ of the changes in the Atlantic in steady state, with the remaining $74 \%$ balanced by changes in the Southern Ocean overturning circulation, in contrast with the fast transient response in section $3 \mathrm{a}$. We test this result using the reduced gravity model with varied NADW formation rates and find an interbasin compensation level of $22 \%$ (Fig. 7), which is close to the estimate here. This low compensation level is consistent with the emphasis on Southern Ocean processes in constraining the AMOC in previous studies (e.g., Marshall and Speer 2012; Ferrari et al. 2014; Sun et al. 2018), which largely focused on the steady state.

\section{c. Response to periodic perturbations to NADW formation}

Here we show the response of the overturning circulation in the runs with periodic perturbations to the NADW formation rate and discuss the dependence of the transient interbasin compensation on the perturbation time scales. With periodic perturbations to the NADW formation rate, the meridional transports at the southern boundary of the basins vary to balance the NADW formation changes (Fig. 8). For a forcing period
$2 \pi / \omega=1000$ years, we show that the Indo-Pacific residual transport $T^{P}$ is roughly opposite to the changes in the Atlantic residual transport $T^{A}$, with the Southern Ocean residual transport $T^{S}$ having a much smaller magnitude.

We quantify the transient interbasin compensation using the absolute value of the slope of $T^{P}$ versus $T^{A}$ over the final forcing period in each of the simulations (Fig. 8b). For forcing periods $2 \pi / \omega$ less than 1000 years, changes in the Indo-Pacific transport compensate approximately $90 \%$ of the Atlantic changes (Fig. 9a), allowing the Southern Ocean to remain largely constant. As the oscillation period increases, the meridional eddy transport has a longer time to adjust and the transient interbasin compensation level decreases (Fig. 9a). The steady-state response in section $3 b$ represents the limit when the forcing period approaches infinity.

\section{Response in the GCM simulations}

In this section, we present results from the MITgcm and the climate model simulations, which include additional dynamics as introduced in section 2. Despite the many simplifications in the reduced gravity model, we find that the reduced gravity model captures most of the features in the more comprehensive GCM simulations regarding the interbasin interactions.

\section{a. $M I T g c m$}

At the end of the MITgcm control run, the restoring temperature in the North Atlantic is abruptly modified 
Reduced gravity model
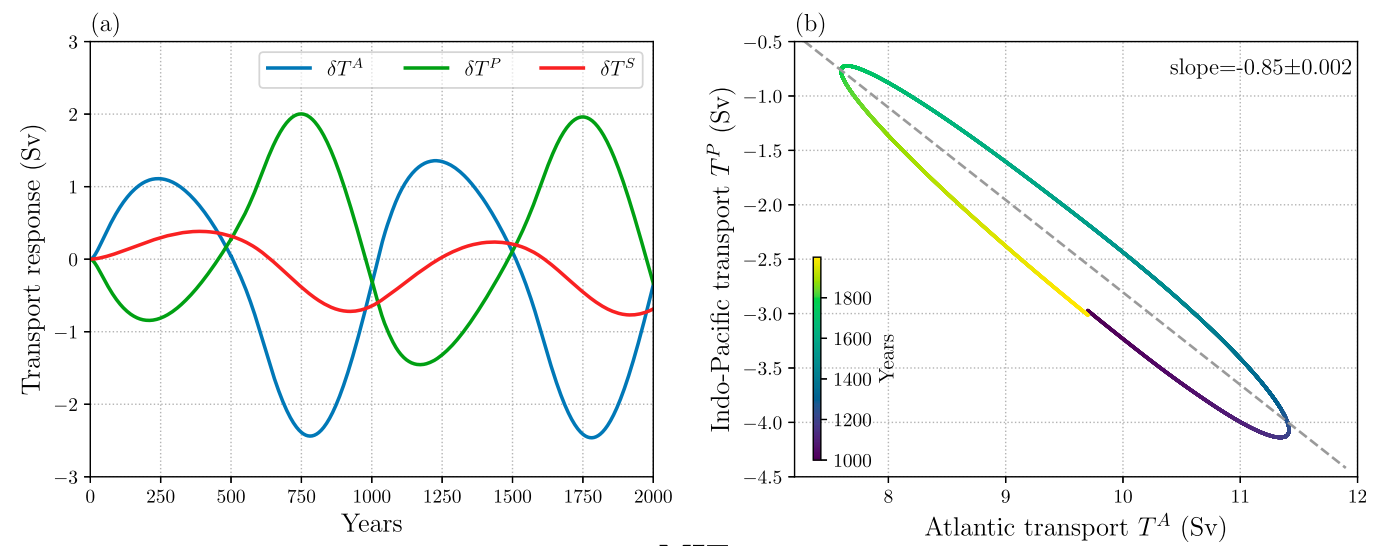

MITgcm
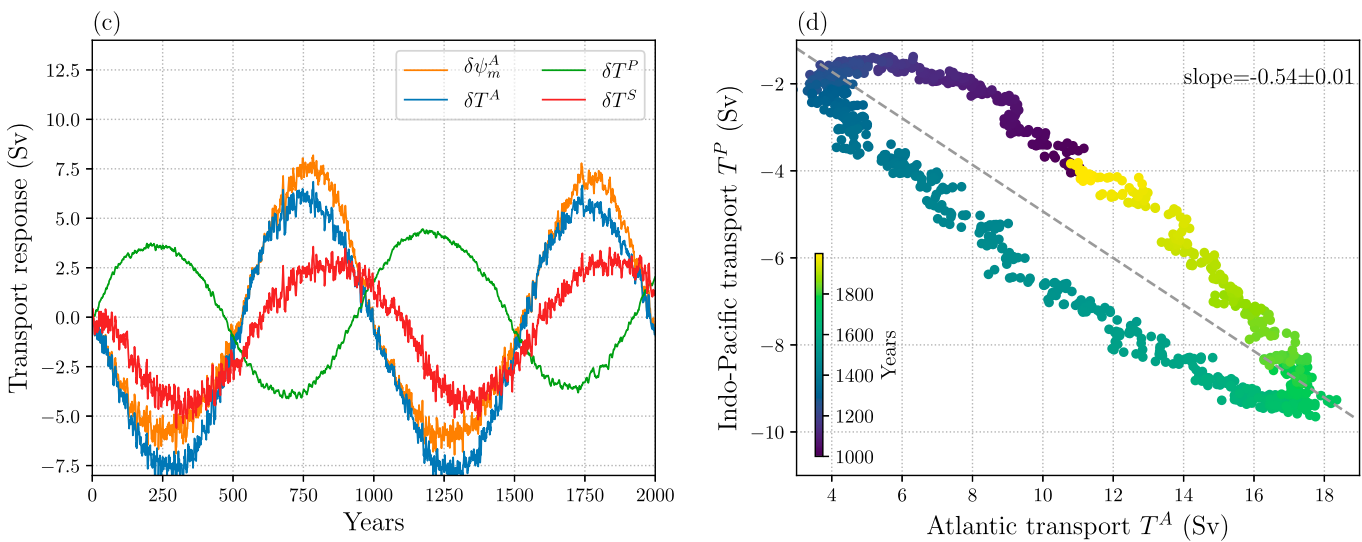

FIG. 8. (a),(c) Response of the overturning circulation to a 1000-yr periodic perturbation in the NADW formation rate [Eqs. (5) and (9)] in (top) the reduced gravity model and (bottom) the MITgcm simulations. (b),(d) The transport in the Indo-Pacific basin is plotted against the Atlantic for the last 1000 years, with the slope calculated using ordinary least squares regression. The transport is evaluated at the southern boundary of the northern basins $\left(45^{\circ} \mathrm{S}\right.$ in the reduced gravity model and $30^{\circ} \mathrm{S}$ in the MITgcm simulations). The transport in the MITgcm simulations is smoothed using a 5 -yr running mean.

and then maintained at a constant value [Eq. (8)]. This warming in the North Atlantic weakens NADW formation, leading to a reduction in the AMOC strength at $30^{\circ} \mathrm{S}$ (Fig. $6 \mathrm{c}$ ). Similar to the reduced gravity model, the surface residual transport of the Atlantic and the Indo-Pacific at $30^{\circ} \mathrm{S}$ show a fast response on multidecadal time scales and a slow response on multicentennial time scales. During the first 50 years after the perturbation, northward and southward surface transport anomalies are established in the Indo-Pacific and the Atlantic basins, respectively. The northward surface transport anomaly in the Indo-Pacific basin compensates much of the changes in the Atlantic basin, such that residual overturning changes in the Southern Ocean are small (Fig. 6c). Interbasin compensation between the Atlantic and Indo-Pacific $\left(-\delta T^{P} / \delta T^{A}\right)$ is roughly $80 \%$ during the first 50 years; it then slowly decreases to around $30 \%$ over a $500-\mathrm{yr}$ period. This reduction in the interbasin compensation is due to the strengthening eddy transport (Fig. 6d). The interbasin compensation at steady state is close to the reduced gravity model at $27 \%$ (Fig. 7), but the time scale associated with the slow response is shorter (Fig. 6). We speculate that this shorter time scale for the adjustment of the Southern Ocean, as compared to the reduced gravity model, is related to the surface buoyancy conditions, as discussed in section 5 .

In response to a periodic perturbation to the restoring temperature in the North Atlantic, the surface transports in the Atlantic and the Indo-Pacific basins at $30^{\circ} \mathrm{S}$ vary periodically (Fig. $8 \mathrm{c}$ ). Similar to the reduced gravity model, the surface transport change in the IndoPacific basin opposes the Atlantic, with the Southern Ocean transport having a smaller magnitude (Fig. 8). The transient interbasin compensation level remains at $\sim 80 \%$ on decadal to centennial time scales for forcing 


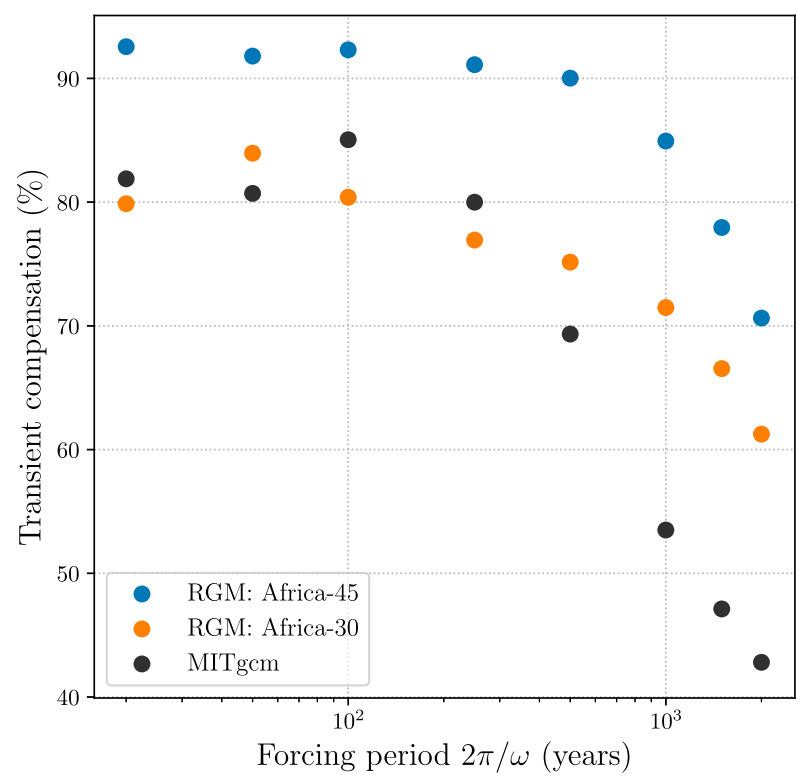

FIG. 9. Dependence of the transient interbasin compensation level (\%) on the forcing period in the reduced gravity model (blue and orange dots) and MITgcm simulations (black dots) with periodic perturbations to the NADW formation rate [Eqs. (5) and (9)].

periods $2 \pi / \omega<500$ years, but then decreases as the forcing time scale becomes longer (Fig. 9). The dependence of the transient interbasin compensation on the forcing time scale is consistent with, but slightly lower than the reduced gravity model. We suggest that part of this difference can be explained by the different model geometry (see section $5 \mathrm{c}$ ).

The response of the basin-scale overturning circulation streamfunctions show similar interbasin compensation as the surface residual transport. In Fig. 10, we present a Hovmöller diagram of the residual-mean overturning circulation streamfunction at $30^{\circ} \mathrm{S}$, mapped to depth coordinates using the mean isopycnal depth in the control run. With a change in the AMOC streamfunction related to surface perturbations in the North Atlantic, the Indo-Pacific overturning circulation responds at approximately the same time and the same depth as the AMOC but with the opposite sign. The overturning circulation response in the Indo-Pacific compensates over $50 \%$ of the AMOC changes, causing the Southern Ocean overturning circulation to experience changes of a smaller magnitude.

\section{b. Transient response of the AMOC in a warming climate}

Climate model simulations consistently project the AMOC strength to decline in the twenty-first century (Cheng et al. 2013). The weakening AMOC is consistent with a reduced NADW formation, but it is potentially in conflict with changes in the Southern Ocean overturning, which strengthens due to stronger Southern Hemisphere westerly winds in a warming climate (Yin 2005). The results above suggest that this conundrum can be resolved by considering the adjustment of the overturning circulation in the Indo-Pacific. Under a reduction in the AMOC strength, the Indo-Pacific develops an overturning circulation anomaly that substantially compensates the AMOC change, such that the AMOC is decoupled from the Southern Ocean. To further explore this mechanism, we examine changes in the meridional overturning circulation in the CESM Large Ensemble simulations for the twenty-first century.

The residual-mean overturning circulation streamfunction is calculated over years 2006-15 and mapped to depth coordinates in the CESM Large Ensemble simulations (Fig. 11). Similar to the MITgcm simulations (Fig. 4), there is a minimum in the Indo-Pacific overturning circulation streamfunction at intermediate depths $(1-3 \mathrm{~km})$ in the Southern Hemisphere that is due to an interbasin overturning circulation. In response to greenhouse gas forcing, the Southern Ocean overturning circulation shows a positive streamfunction anomaly at the end of the twenty-first century compared to years 2006-15 (Fig. 11b), consistent with a stronger westerly wind forcing. In contrast to the Southern Ocean changes, the AMOC weakens by roughly $10 \mathrm{~Sv}$ (Fig. 11d) over this same period. The weakening of the AMOC during these 100 years is accomplished primarily through geostrophic transport adjustment, which is associated with vertical displacements of the isopycnals on the meridional boundaries. This suggests opposite overturning circulation changes between the Atlantic and the Indo-Pacific close to $30^{\circ} \mathrm{S}$. Indeed, there is a positive streamfunction anomaly in the Indo-Pacific overturning circulation at the end of the twenty-first century (Fig. 11d), which substantially compensates the AMOC weakening, reconciling the different response between the AMOC and the Southern Ocean overturning circulation.

The positive overturning circulation streamfunction anomaly in the Indo-Pacific basin represents a northward transport anomaly in the surface and a southward transport anomaly in the deep ocean. We quantify the changes in the surface transport above the isopycnal interface $b_{m}$ (thick green lines in Fig. 11c). We find a $1.03 \mathrm{~Sv}$ decade ${ }^{-1}$ reduction in the Atlantic northward surface transport and a $0.84 \mathrm{~Sv}$ decade $^{-1}$ reduction in the Indo-Pacific southward surface transport (Fig. 12). Taken together, this suggests a transient interbasin compensation of around $80 \%$, close to the MITgcm simulations on centennial time scales (e.g., $2 \pi / \omega=250$ years in Fig. 9). We repeated the calculation over all 40 Large 
(a) N.A. temperature perturbation $\left({ }^{\circ} \mathrm{C}\right)$
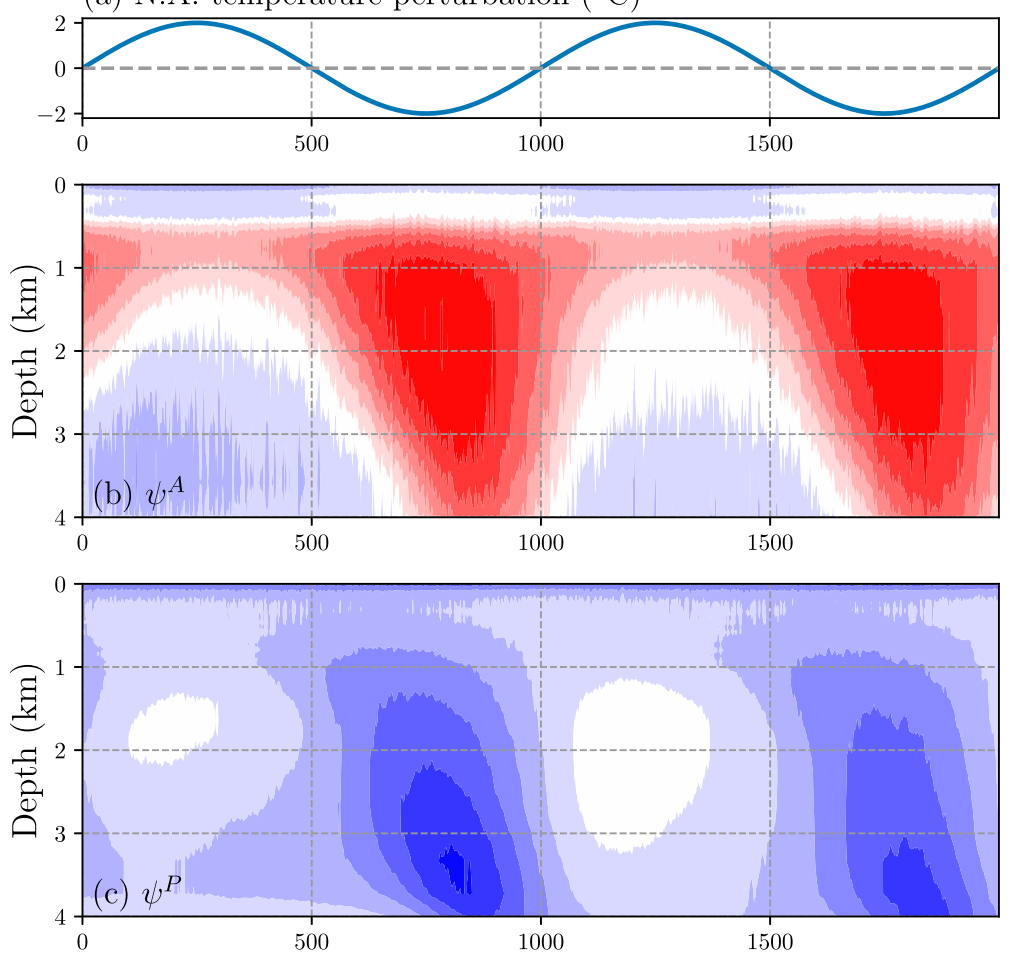

16.5

Ensemble members, and the results are all similar to Fig. 11.

Because of the vertical temperature gradient, these changes in the meridional overturning circulation correspond to an anomalous southward heat transport in the Atlantic basin and an anomalous northward heat transport in the southern Indo-Pacific (Figs. 13a,b). The anomalous northward heat transport does not extend to the northern Indo-Pacific basin (Fig. 13b), because the Indo-Pacific overturning circulation response is mainly limited to the Southern Hemisphere (Fig. 11d).
We quantify the changes in the meridional heat transport at $30^{\circ} \mathrm{S}$ during years 2006-2100 (blue lines in Figs. $13 \mathrm{c}, \mathrm{d}$ d) as well as the component due to the mean circulation (red lines in Figs. 13c,d), which is mostly geostrophic. We find a $3.1 \mathrm{TW} \mathrm{yr}^{-1}$ trend in the IndoPacific heat transport and a $-2.2 \mathrm{TW} \mathrm{yr}^{-1}$ trend in the Atlantic heat transport. The opposite signs of the meridional heat transport trends at $30^{\circ} \mathrm{S}$ in the two basins suggests a redistribution of heat from the Atlantic basin to the Indo-Pacific basin in the warming climate, which is primarily accomplished by the mean circulation (cf. the 

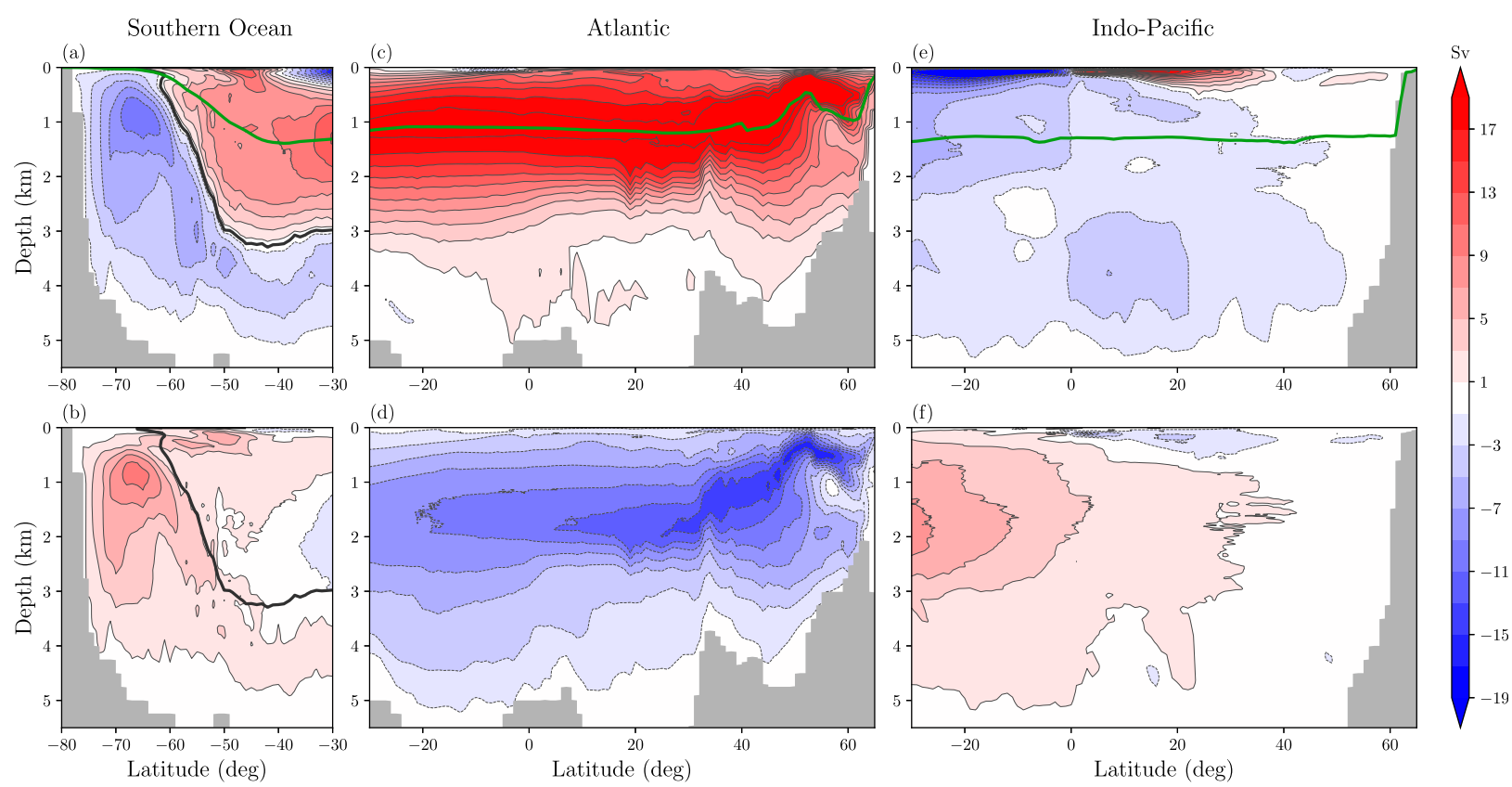

FIG. 11. Meridional overturning circulation and its changes in the third member of the CESM Large Ensemble simulations for the twenty-first century: Residual-mean overturning circulation streamfunction (Sv) in (a) the Southern Ocean, (c) the Atlantic Ocean, and (e) the Indo-Pacific basin, averaged over 2006-15, and changes in the residual-mean overturning circulation streamfunction (Sv) in (b) the Southern Ocean, (d) the Atlantic Ocean, and (f) the Indo-Pacific basin between 2006-10 and 2091-2100. The thick black contours in (a) and (b) show the boundary between the upper and lower overturning circulation cell in the Southern Ocean. The green contours in (a), (c), and (e) show the isopycnal interface as defined in Eq. (12) for CESM. The upward displacement of streamlines at around $55^{\circ} \mathrm{N}$ in the North Atlantic [(c) and (d)] is due to a shoaling of the isopycnals associated with the subpolar gyre.

blue lines with the red lines in Fig. 13). Additionally, the AMOC weakening deepens the isopycnals as suggested by the overturning circulation streamfunction anomaly in both the Atlantic and the Indo-Pacific in Fig. 11 (cf. Jansen et al. 2018; Thompson et al. 2019). This deepening of the isopycnals is consistent with the reduced gravity model and could contribute substantially to the warming in these two basins, particularly in the intermediate depths (Figs. 13e,f).

\section{Discussion}

\section{a. Summary of response mechanisms}

The reduced gravity model highlights that the ocean response to a perturbation in NADW formation occurs through various processes, spanning a range of time scales. Here, we review the key mechanisms that enable the interbasin compensation between the Atlantic and the Indo-Pacific, as well as the associated characteristic time scales (Fig. 14). The reduction in NADW formation results in a deepening of the interface, localized to the North Atlantic. The first response to this deepening is a propagation of the interface displacement southward via Kelvin waves (Fig. 5b). After crossing the equator, the Kelvin waves propagate the interface displacement to the southern boundary of the Atlantic basin $y_{0}$ over a period of roughly 1 month. This then modifies the meridional geostrophic transport at $y_{0}$ in both the Atlantic and Indo-Pacific basins, which depends on the change in zonal difference of interface depth, $\Delta h=h_{e}-h_{w}$. The geostrophic transports in the Atlantic and Indo-Pacific basins have the same magnitudes but opposite signs. While perturbations along the eastern boundary of the basin are effectively radiated into the interior on a decadal time scale, this does not modify the meridional eddy transport substantially. The eddy transport responds to a change in the Southern Ocean isopycnal slope, which in this model is directly related to the zonally averaged interface depth at $y_{0}$. The change in the zonally averaged interface depth primarily occurs through volume flux convergence into the upper layer on multicentennial time scales. Thus, on short time scales, the Indo-Pacific approximately compensates changes in the AMOC.

Eventually, this compensation between the Atlantic and Indo-Pacific weakens. This occurs because over centennial to multicentennial time scales, the net displacement of the interface in both basins modifies the strength of the eddy overturning in the Southern Ocean, 

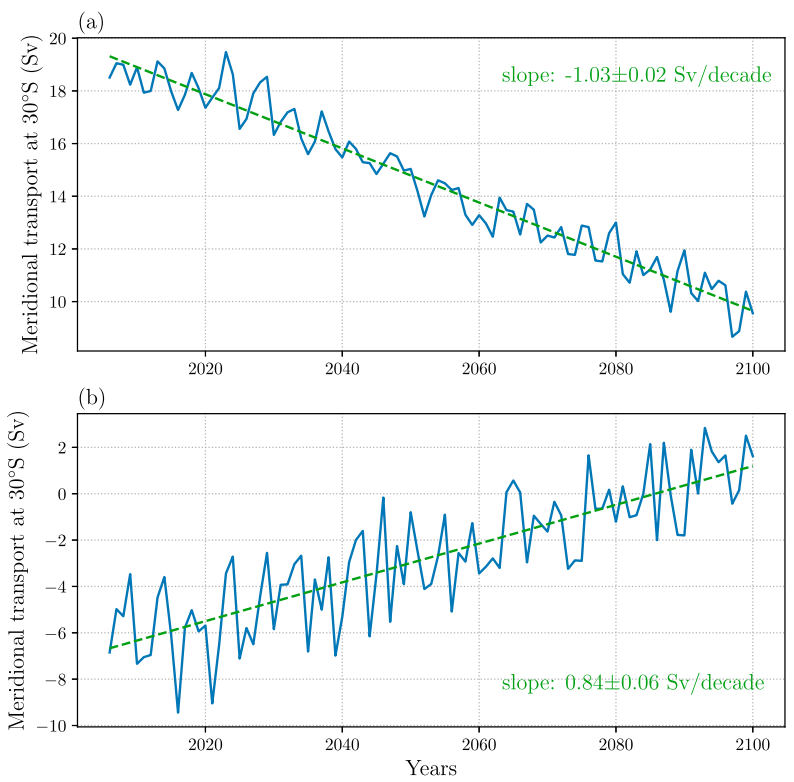

FIG. 12. Meridional transport $T^{i}(\mathrm{~Sv})$ above the isopycnal interface $b_{m}$ (green line in Fig. 11c) at $30^{\circ} \mathrm{S}$ in (a) the Atlantic basin and (b) the Indo-Pacific basin in the third member of the CESM Large Ensemble simulations. The green dashed lines show the linear trend in the meridional transport $T^{i}$, with the slope included in each panel.

which in this reduced gravity model is equal to the implied surface watermass transformation in the Southern Ocean. This change in the Southern Ocean overturning is required to balance the changes in NADW formation. For example, as $T_{\text {NADw }}$ weakens, the interface deepens, and the Southern Ocean isopycnal slope steepens. This strengthens the eddy component of the Southern Ocean overturning, which implies less dense water is transformed into lighter (upper layer) waters (Thompson et al. 2019). This change in the transformation rate relieves the burden on the Indo-Pacific to accommodate changes in the Atlantic overturning. Yet, because of the constraint of deepening the entire upper layer in the northern basins, changes to the Southern Ocean overturning only become significant after at least 100 years. A simple scaling for the Southern Ocean adjustment is challenging, because the interface depth responds to both low-latitude diapycnal transformation and an evolving surface transformation in the Southern Ocean; this is especially true in more realistic geometries. Last, we note that changes to overturning in the Atlantic and Pacific adjust over a multidecadal period, which is set by the gyre spinup/spin-down dynamics in response to a change in surface forcing.

Despite the many simplifications made in the reduced gravity model, we show that similar responses of the overturning circulation are also found in more comprehensive
GCM simulations. These results together highlight the importance of the Indo-Pacific basin in mediating the transient responses of the global ocean overturning circulation to surface forcing perturbations.

\section{b. Transient versus equilibrium responses}

We show in this study that the Indo-Pacific can balance the AMOC changes in transient responses through interbasin exchange. The transient interbasin compensation stands in contrast with the steady-state response, in which the Southern Ocean upwelling plays a more important role in balancing the AMOC changes. The difference between the transient response and the equilibrium response is not surprising. In a recent study using a single-basin model, Jansen et al. (2018) highlights the different response time scales of the overturning circulation in response to surface perturbations in the North Atlantic and the Southern Ocean. However, their model does not include a representation of the interbasin exchange, which we show here is key to understanding the transient response of the global ocean overturning circulation. A single-basin model has been extensively used in previous studies of the overturning circulation (e.g., Gnanadesikan 1999; Jones et al. 2011; Allison et al. 2011; Munday et al. 2013), but our results suggest that the transient response of these systems may should be interpreted cautiously.

\section{c. Impact of the model geometry}

In section 3, we explored the interbasin compensation in a reduced gravity model configuration in which both narrow continents extend to $45^{\circ} \mathrm{S}$ (Africa-45). Now we discuss a more realistic configuration in which the idealized Africa extends to $30^{\circ} \mathrm{S}$ (Africa-30; same as the MITgcm simulations).

With a shorter continent to the east of the Atlantic basin, a wind-driven supergyre forms between $30^{\circ}$ and $45^{\circ} \mathrm{S}$ (cf. Ridgway and Dunn 2007), which also has a strong western boundary current. In the boundary current, the momentum balance is

$$
g^{\prime} \frac{\partial h}{\partial y} \approx A_{h} \frac{\partial^{2} v}{\partial x^{2}} .
$$

This relationship shows that a meridional pressure gradient can be supported by friction, parameterized with a horizontal viscosity, within the western boundary current. This implies that the interface depth on the western boundary $\left(h_{w}^{A}\right)$ of the Atlantic basin differs from the eastern boundary of the Indo-Pacific basin $\left(h_{e}^{P}\right)$ at $30^{\circ} \mathrm{S}$ [cf. Eq. (19)]. Yet, during the fast response of the overturning circulation to an NADW formation perturbation, 

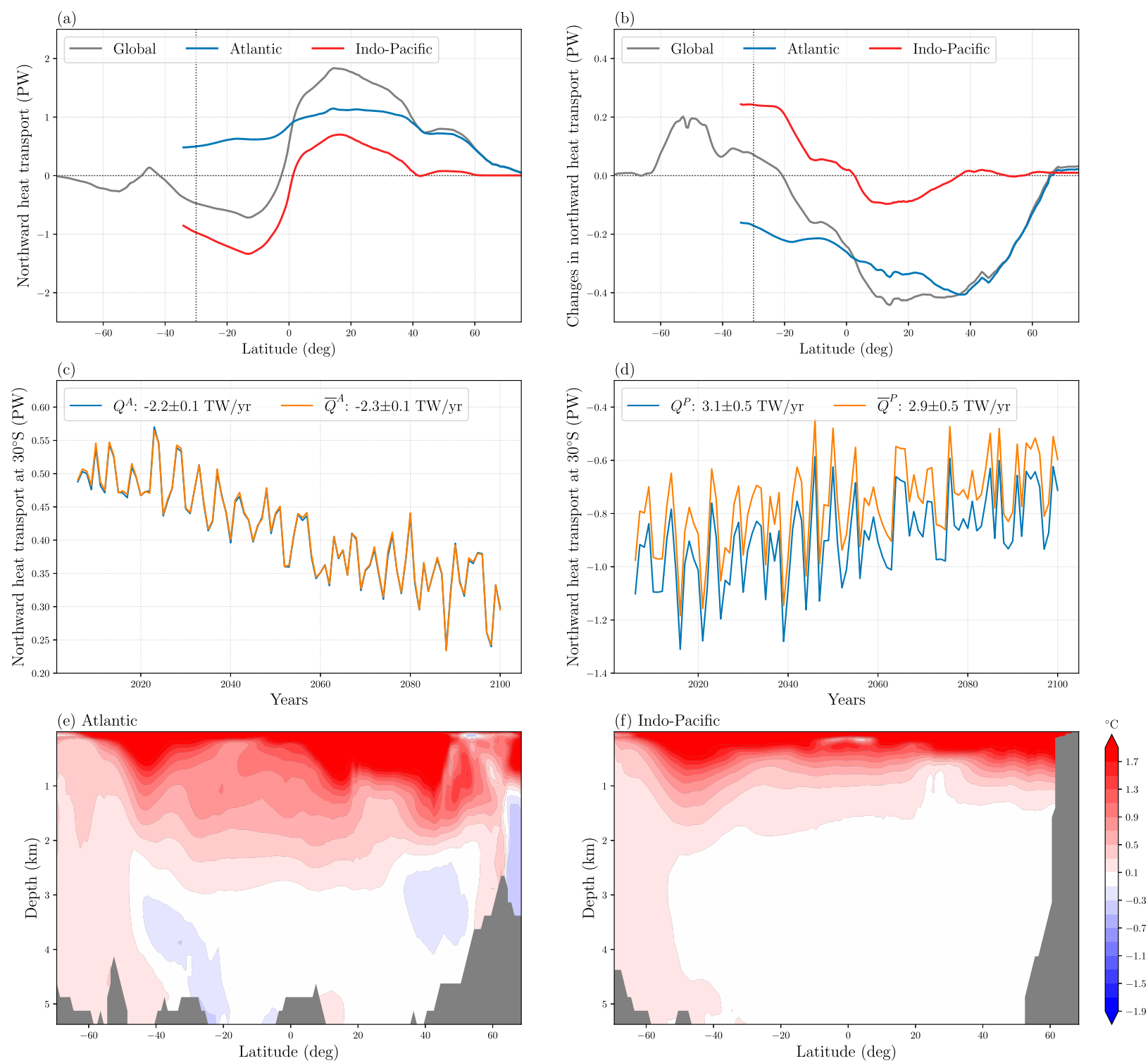

FIG. 13. Changes in the meridional heat transport and warming of the ocean in one of the CESM Large Ensemble simulations for the twenty-first century: (a) Meridional heat transport (PW) in the Atlantic, the Indo-Pacific, and the global ocean, averaged between 2006 and 2015. (b) Change in the meridional heat transport (PW) from the average during 2006-15 to the average during 2091-2100. Time series of the annual-mean meridional heat transport (PW) at $30^{\circ} \mathrm{S}$ in the (c) Atlantic and (d) Indo-Pacific basins. Blue and red lines represent the total meridional heat transport $\left[Q^{i}\right.$ in Eq. (14)] and the heat transport due to mean flows $\left[\bar{Q}^{i}\right.$ in Eq. (15)], respectively. The linear trends in $Q^{i}$ and $\bar{Q}^{i}$ are calculated using ordinary least squares regression. Changes in the zonal-mean temperature $\left({ }^{\circ} \mathrm{C}\right)$ in the (e) Atlantic and (f) Indo-Pacific basins. The temperature change south of $30^{\circ} \mathrm{S}$ in the Southern Ocean is calculated over the Atlantic sector in (e) and the Indo-Pacific sector in (f). Note that $1 \mathrm{PW}=10^{3} \mathrm{TW}=10^{15} \mathrm{~W}$.

the difference in these interface depths, $h_{e}^{P}-h_{w}^{A}$, remains approximately constant (not shown), i.e.,

$$
\delta h_{e}^{P} \approx \delta h_{w}^{A} .
$$

This occurs because the supergyre remains roughly unchanged due to the constant wind stress forcing.

Unlike the Africa- 45 scenario, the transient response of the geostrophic transports in the Atlantic and the
Indo-Pacific at $30^{\circ} \mathrm{S}$ do not fully compensate. This can be seen by applying a first-order Taylor expansion of the geostrophic transport [Eq. (17)], which gives

$$
\delta T_{G}^{A}+\delta T_{G}^{P} \approx \frac{g^{\prime}}{f_{0}}\left(h_{e}^{P}-h_{w}^{A}\right) \delta h_{e}^{P} \neq 0
$$

This suggests a lower interbasin compensation level in Africa-30 than in Africa-45. Further reduced gravity 


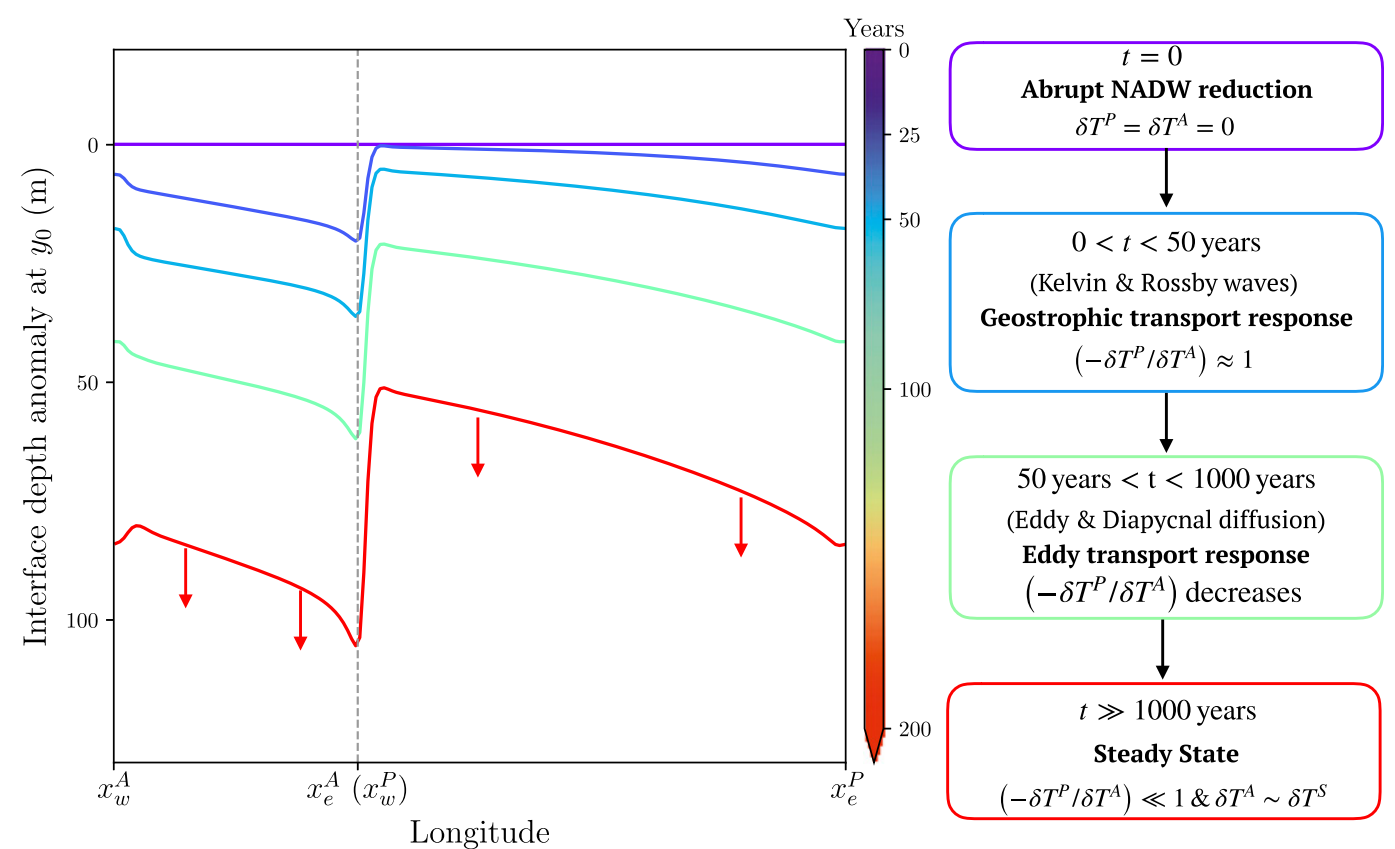

FIG. 14. (left) Evolution of the interface depth anomaly at $y_{0}$ and (right) key dynamical processes that describe the adjustment of the overturning circulation in the reduced gravity model. The colors of the contours in the left panel correspond to the boxes on the right, and they indicate the time scale following the perturbation during which these processes are active. The red arrows in the left panel indicate further deepening of the interface on multicentennial time scales.

model simulations show that this change of model geometry reduces the transient interbasin compensation level in the periodic perturbation runs by around $10 \%$, bringing the reduced gravity model closer to the MITgcm simulations (Fig. 9). Nevertheless, there remains a significant degree of compensation, even in the presence of a supergyre.

\section{d. Impact of surface buoyancy conditions}

In the reduced gravity model and MITgem simulations, we use a relaxation boundary condition for surface buoyancy forcing in the Southern Ocean. However, previous studies have suggested that the surface buoyancy forcing is dominated by surface freshwater flux in the Southern Ocean (e.g., Abernathey et al. 2016; Sun et al. 2016), which may be better represented as a surface buoyancy flux boundary condition. With a fixed surface buoyancy flux in the Southern Ocean, the outcropping position of isopycnals have more freedom to migrate meridionally (Thompson et al. 2019). This might suggest a different response time scale for the Southern Ocean transport from Eq. (27) and thus a different interbasin compensation from our model.

We investigated the impact of using a fixed surface buoyancy flux in the Southern Ocean with the two-layer box model from Thompson et al. (2019), and find that the transient interbasin compensations on forcing time scales $2 \pi / \omega$ less than 1000 years are not substantially affected by the type of surface boundary condition (not shown). With a fixed surface buoyancy flux, the Southern Ocean overturning circulation, which is determined by the outcropping latitude of the interface in the Southern Ocean, responds to NADW formation changes on multicentennial time scales (Thompson et al. 2019, their Fig. 4). This response time scale of the Southern Ocean overturning circulation is somewhat shorter than the estimate in Eq. (27), but it is longer than the fast response due to wave processes. Therefore, the application of a fixed surface buoyancy flux in the Southern Ocean may not be expected to substantially affect the transient interbasin compensation on decadal to centennial time scales. This is further supported by the CESM Large Ensemble coupled simulations, which show high transient interbasin compensation between the Atlantic and the Indo-Pacific basins over the analyzed 100 years, in agreement with both the reduced gravity model and the MITgcm simulations.

\section{e. Impact of including a more realistic wind forcing in the reduced gravity model}

In the reduced gravity model, the wind stress forcing is confined to the Southern Ocean (Fig. 2b) 
for simplicity, and there are no wind-driven gyres in the basins. To explore the impact of gyres, we completed a simulation forced by the wind stress from Fig. 3b. This altered low-latitude surface forcing causes the transient interbasin compensation level (Fig. 9) to change by less than $2 \%$, because the eddy response time scale is independent of the wind stress forcing [Eq. (27)]. However, a slight increase in the wind stress forcing at the southern boundary of the basins strengthens the northward Ekman transport and leads to a deeper basin-average interface depth (not shown). This causes the steady-state interbasin compensation level (Fig. 7) to decrease from $22 \%$ to $16 \%$ [Eq. (35)].

\section{Summary}

Recent developments in understanding the global ocean overturning circulation have highlighted the Southern Ocean upwelling as the southern limb of the AMOC, suggesting that the magnitude of these components are closely linked (e.g., Marshall and Speer 2012). However, comprehensive climate models predict the AMOC strength to decline in response to greenhouse gas forcing, which appears to contradict the projected changes in the Southern Ocean surface forcing. In this study, we propose that modifications to the Indo-Pacific overturning circulation can reconcile the differences between the AMOC changes and the Southern Ocean surface forcing in a changing climate.

Using a hierarchy of ocean and climate models, we explored the transient responses of the global ocean overturning circulation to NADW formation perturbations. We found that, in response to a change in the NADW formation rate, the Indo-Pacific provides the first response to the AMOC changes through wave processes, whereas the Southern Ocean overturning circulation responds on much longer time scales due to eddy diffusion processes. On a time scale less than 100 years, modifications to the volume transport leaving the Atlantic basin can be compensated through an interbasin exchange with the Indo-Pacific basin. It is only on much longer time scales that the Southern Ocean overturning circulation becomes more strongly linked to changes in the AMOC.

Associated with the weakening AMOC strength in a warming climate, the results suggest that an anomalous overturning circulation develops in the Indo-Pacific which substantially compensates the Atlantic changes through interbasin exchanges, at least over time scales of many decades. Thus, the interbasin exchanges reconcile the differences between the AMOC changes and the Southern Ocean surface forcing in a warming climate. Beyond centennial time scales, the Southern Ocean surface forcing plays an increasing role in constraining the AMOC, and eventually the AMOC strength may recover due to changes in the Southern Ocean processes (Jansen et al. 2018; Newsom et al. 2020, manuscript submitted to Proc. Natl. Acad. Sci. USA).

Understanding the transient response of the global ocean overturning is key to constraining the role of ocean circulation in a changing climate (e.g., Armour et al. 2016). The results of this study highlight the importance of the interbasin overturning circulation in the transient response of the global ocean overturning circulation to surface forcing perturbations. These results suggest that interbasin exchanges could play an important role in past and future climate changes by regulating the heat and tracer distributions between different basins.

Acknowledgments. Without implying their endorsement, we thank Andrew Stewart, Geoffrey Vallis, and Shang-Ping Xie for helpful discussions. We are also grateful for Dan Jones and an anonymous reviewer for their helpful comments. This work was supported by National Science Foundation (NSF) Grants OPP-1644172 and OPP-1643445. The model simulations in this study were carried out on Cheyenne (doi:10.5065/D6RX99HX), which is provided by NCAR's Computational and Information System Laboratory, sponsored by the National Science Foundation. The source code for the reduced gravity model is available online (https:// stsun.github.io/files/Sun-Thompson-Eisenman-2020JPORGM.tar). The code for calculating the isopycnal overturning circulation streamfunction from the nominal $1^{\circ}$-resolution CESM output is also available (https:// stsun.github.io/files/Sun-Thompson-Eisenman-2020JPOROC.tar).

\section{REFERENCES}

Abernathey, R. P., I. Cerovecki, P. R. Holland, E. Newsom, M. Mazloff, and L. D. Talley, 2016: Water-mass transformation by sea ice in the upper branch of the Southern Ocean overturning. Nat. Geosci., 9, 596-601, https://doi.org/10.1038/ ngeo2749.

Allison, L. C., H. L. Johnson, and D. P. Marshall, 2011: Spin-up and adjustment of the Antarctic circumpolar current and global pycnocline. J. Mar. Res., 69, 167-189, https://doi.org/10.1357/ 002224011798765330.

Armour, K. C., J. Marshall, J. R. Scott, A. Donohoe, and E. R. Newsom, 2016: Southern Ocean warming delayed by circumpolar upwelling and equatorward transport. Nat. Geosci., 9, 549-554, https://doi.org/10.1038/ngeo2731.

Bryan, K., and L. Lewis, 1979: A water mass model of the world ocean. J. Geophys. Res., 84, 2503-2517, https://doi.org/10.1029/ JC084iC05p02503. 
Buckley, M. W., and J. Marshall, 2016: Observations, inferences, and mechanisms of the Atlantic meridional overturning circulation: A review. Rev. Geophys., 54, 5-63, https://doi.org/ 10.1002/2015RG000493.

Cessi, P., 2019: The global overturning circulation. Annu. Rev. Mar. Sci., 11, 249-270, https://doi.org/10.1146/annurev-marine010318-095241.

Cheng, W., J. C. Chiang, and D. Zhang, 2013: Atlantic Meridional Overturning Circulation (AMOC) in CMIP5 models: RCP and historical simulations. J. Climate, 26, 7187-7197, https:// doi.org/10.1175/JCLI-D-12-00496.1.

Ferrari, R., M. F. Jansen, J. F. Adkins, A. Burke, A. L. Stewart, and A. F. Thompson, 2014: Antarctic Sea ice control on ocean circulation in present and glacial climates. Proc. Natl. Acad. Sci. USA, 111, 8753-8758, https://doi.org/ 10.1073/pnas.1323922111.

— , L.-P. Nadeau, D. P. Marshall, L. C. Allison, and H. L. Johnson, 2017: A model of the ocean overturning circulation with two closed basins and a reentrant channel. J. Phys. Oceanogr., 47, 2887-2906, https://doi.org/10.1175/JPO-D-160223.1.

Gent, P. R., and J. C. McWilliams, 1990: Isopycnal mixing in ocean circulation models. J. Phys. Oceanogr., 20, 150-155, https://doi.org/10.1175/1520-0485(1990)020<0150:IMIOCM > 2.0.CO;2.

Gill, A. E., 1982: Atmosphere-Ocean Dynamics. Academic Press, $662 \mathrm{pp}$.

Gnanadesikan, A., 1999: A simple predictive model for the structure of the oceanic pycnocline. Science, 283, 2077-2079, https://doi.org/10.1126/science.283.5410.2077.

Goldsbrough, G. R., 1933: Ocean currents produced by evaporation and precipitation. Proc. Roy. Soc. London, A141, 512517, https://doi.org/10.1098/rspa.1933.0135.

Gordon, A. L., 1986: Interocean exchange of thermocline water. J. Geophys. Res. Oceans, 91, 5037-5046, https://doi.org/10.1029/ JC091iC04p05037.

Gregory, J., and Coauthors, 2005: A model intercomparison of changes in the Atlantic thermohaline circulation in response to increasing atmospheric $\mathrm{CO}_{2}$ concentration. Geophys. Res. Lett., 32, L12703, https://doi.org/10.1029/ 2005GL023209.

Haney, R. L., 1971: Surface thermal boundary condition for ocean circulation models. J. Phys. Oceanogr., 1, 241-248, https://doi.org/10.1175/1520-0485(1971)001<0241:STBCFO $>$ 2.0.CO;2

Held, I. M., 2005: The gap between simulation and understanding in climate modeling. Bull. Amer. Meteor. Soc., 86, 1609-1614, https://doi.org/10.1175/BAMS-86-11-1609.

Holmes, R. M., J. D. Zika, R. Ferrari, A. F. Thompson, E. R. Newsom, and M. H. England, 2019: Atlantic Ocean heat transport enabled by Indo-Pacific heat uptake and mixing. Geophys. Res. Lett., 46, 13 939-13 949, https://doi.org/10.1029/ 2019GL085160.

Jansen, M. F., L.-P. Nadeau, and T. M. Merlis, 2018: Transient versus equilibrium response of the ocean's overturning circulation to warming. J. Climate, 31, 5147-5163, https://doi.org/ 10.1175/JCLI-D-17-0797.1.

Johnson, H. L., and D. P. Marshall, 2002: Localization of abrupt change in the north Atlantic thermohaline circulation. Geophys. Res. Lett., 29, 1083, https://doi.org/10.1029/ 2001 GL014140.

—, and —, 2004: Global teleconnections of meridional overturning circulation anomalies. J. Phys. Oceanogr., 34,
1702-1722, https://doi.org/10.1175/1520-0485(2004)034<1702: GTOMOC $>2.0 . \mathrm{CO} ; 2$.

_ , P. Cessi, D. P. Marshall, F. Schloesser, and M. A. Spall, 2019: Recent contributions of theory to our understanding of the Atlantic meridional overturning circulation. J. Geophys. Res. Oceans, 124, 5376-5399, https://doi.org/ 10.1029/2019JC015330.

Jones, C. S., and P. Cessi, 2016: Interbasin transport of the meridional overturning circulation. J. Phys. Oceanogr., 46, 11571169, https://doi.org/10.1175/JPO-D-15-0197.1.

Jones, D. C., T. Ito, and N. S. Lovenduski, 2011: The transient response of the Southern Ocean pycnocline to changing atmospheric winds. Geophys. Res. Lett., 38, L15604, https:// doi.org/10.1029/2011GL048145.

Kay, J., and Coauthors, 2015: The Community Earth System Model (CESM) large ensemble project: A community resource for studying climate change in the presence of internal climate variability. Bull. Amer. Meteor. Soc., 96, 1333-1349, https:// doi.org/10.1175/BAMS-D-13-00255.1.

Lumpkin, R., and K. Speer, 2007: Global ocean meridional overturning. J. Phys. Oceanogr., 37, 2550-2562, https://doi.org/ 10.1175/JPO3130.1.

Marshall, J., and K. Speer, 2012: Closure of the meridional overturning circulation through Southern Ocean upwelling. Nat. Geosci., 5, 171-180, https://doi.org/10.1038/ngeo1391.

—, A. Adcroft, C. Hill, L. Perelman, and C. Heisey, 1997: A finite-volume, incompressible Navier Stokes model for studies of the ocean on parallel computers. J. Geophys. Res., 102, 5753-5766, https://doi.org/10.1029/96JC02775.

Munday, D. R., H. L. Johnson, and D. P. Marshall, 2013: Eddy saturation of equilibrated circumpolar currents. J. Phys. Oceanogr., 43, 507-532, https://doi.org/10.1175/JPO-D-12095.1 .

Munk, W. H., and E. Palmén, 1951: Note on the dynamics of the Antarctic circumpolar current. Tellus, 3, 53-55, https://doi.org/ 10.3402/tellusa.v3i1.8609.

Newsom, E. R., and A. F. Thompson, 2018: Reassessing the role of the Indo-Pacific in the ocean's global overturning circulation. Geophys. Res. Lett., 45, 12 422-12 431, https://doi.org/10.1029/ 2018GL080350.

Ridgway, K., and J. Dunn, 2007: Observational evidence for a southern hemisphere oceanic supergyre. Geophys. Res. Lett., 34, L13612, https://doi.org/10.1029/2007GL030392.

Sigman, D. M., M. P. Hain, and G. H. Haug, 2010: The polar ocean and glacial cycles in atmospheric $\mathrm{CO}_{2}$ Nature, 466, 47-55, https://doi.org/10.1038/nature09149.

Sun, S., I. Eisenman, and A. L. Stewart, 2016: The influence of Southern Ocean surface buoyancy forcing on glacialinterglacial changes in the global deep ocean stratification. Geophys. Res. Lett., 43, 8124-8132, https://doi.org/10.1002/ 2016GL070058.

,-- , and 2 - 2018: Does Southern Ocean surface forcing shape the global ocean overturning circulation? Geophys. Res. Lett., 45, 2413-2423, https://doi.org/10.1002/ 2017GL076437.

Talley, L. D., 2013: Closure of the global overturning circulation through the Indian, Pacific, and Southern Oceans: Schematics and transports. Oceanography, 26, 80-97, https://doi.org/10.5670/ oceanog.2013.07.

Thompson, A. F., A. L. Stewart, and T. Bischoff, 2016: A multibasin residual-mean model for the global overturning circulation. J. Phys. Oceanogr., 46, 2583-2604, https://doi.org/10.1175/ JPO-D-15-0204.1. 
S. K. Hines, and J. F. Adkins, 2019: A Southern Ocean mechanism for the inter-hemispheric coupling and phasing of the bipolar seesaw. J. Climate, 32, 4347-4365, https://doi.org/ 10.1175/JCLI-D-18-0621.1.

Toggweiler, J., and B. Samuels, 1995: Effect of Drake Passage on the global thermohaline circulation. Deep-Sea Res. I, 42, 477-500, https://doi.org/10.1016/0967-0637(95)00012-U.

Wolfe, C. L., and P. Cessi, 2011: The adiabatic pole-to-pole overturning circulation. J. Phys. Oceanogr., 41, 1795-1810, https:// doi.org/10.1175/2011JPO4570.1.
Yin, J. H., 2005: A consistent poleward shift of the storm tracks in simulations of 21st century climate. Geophys. Res. Lett., 32, L18701, https://doi.org/10.1029/2005GL023684.

Zhang, R., 2010: Latitudinal dependence of Atlantic Meridional Overturning Circulation (AMOC) variations. Geophys. Res. Lett., 37, L16703, https://doi.org/10.1029/2010GL044474.

Zhao, J., and W. Johns, 2014: Wind-driven seasonal cycle of the Atlantic meridional overturning circulation. J. Phys. Oceanogr., 44, 1541-1562, https://doi.org/10.1175/JPO-D13-0144.1. 